\title{
LA JURISDICCIÓN ESPECIAL PARA LA PAZ [JEP], LA LEY ESTATUTARIA DE LA ADMINISTRACIÓN DE JUSTICIA Y SUS VICISITUDES*
}

\section{The Special Jurisdiction for Peace, the Statutory Law of the Administration of Justice and its vicissitudes}

Sergio Roberto Matias Camargo**

Universidad Libre. Bogotá D. C., Colombia

sergio.matias@unilibre.edu.co

Recepción: 3 de octubre de 2018. Aceptación: 23 de febrero de 2019.

DOI: http://dx.doi.org/10.21017/Rev.Repub.2019.v27.a66

\section{RESUMEN}

Aprobado el Proyecto de Ley Estatutaria de la Administración de Justicia en la Jurisdicción Especial para la Paz, fue remitido a la Corte Constitucional para su control automático; declarado constitucional, fue enviado a la Presidencia de la República. El presidente Iván Duque lo impugnó con seis objeciones, remitidas al Congreso; estas fueron negadas y el Proyecto fue enviado a la Corte Constitucional, ratificado en su constitucionalidad inicial. Finalmente, fue sancionado por el presidente de la República, con su reiteración de las objeciones, como necesarias, en medio de un ambiente de hostilidad

* Artículo resultado del proyecto de investigación El Constitucionalismo Democrático contemporáneo-Cultura Constitucional, Derecho Público y Sistema, realizado en el Grupo de Investigaciones Socio jurídicas del Centro de Investigaciones Socio jurídicas de la Facultad Derecho de la Universidad Libre, (Código 11010113), reconocido por Colciencias como Grupo Colombiano de Investigación Científica y clasificado en la Categoría A. COL0016837.

** Doctor en Sociología Jurídica e Instituciones Políticas de la Universidad Externado de Colombia. Magíster en Investigación Social Interdisciplinaria de la Universidad Distrital Francisco José de Caldas. Especialista en Derecho Público, Ciencia y Sociología Política de las universidades Externado de Colombia, Complutense de Madrid y de Estudios de Milán. Especialista en Derecho Constitucional y Abogado de la Universidad Libre de Bogotá. Investigador asociado de Colciencias. Docente titular de la Facultad de Derecho de la Universidad Libre de Bogotá en las cátedras de Ciencia Política (Pregrado), Servicios Públicos Domiciliarios (Maestría), Teoría del Derecho e Investigación Jurídica (Doctorado). Editor de la revista Diálogos de Saberes, indexada por Colciencias. sergiomatyas@hotmail.com 
del Gobierno Nacional, el la Fiscalía General, y las fuerzas contrarias a los Acuerdos de Paz, que ponen en riesgo la JEP. La existencia y garantía del funcionamiento de la JEP, la implementación justa y necesaria de los Acuerdos de Paz, el freno de las actuales amenazas a la democracia y su existencia dependen de la solidaridad y el respaldo masivos de las fuerzas democráticas, que reversen el avance de las fuerzas retardatarias, el autoritarismo y las corrientes neofascistas, que bajo las banderas del «estado de opinión», pretenden suplantar el Estado constitucional de derecho. Se analizan los avances y obstáculos de la JEP, en el actual contexto sociopolítico colombiano. Se utiliza un enfoque crítico y socio jurídico, el método histórico y el lógico, el análisis y la síntesis, las fuentes primarias y secundarias y se hace análisis documental.

Palabras clave: Jurisdicción Especial para la Paz, Ley Estatutaria de la Administración de Justicia, Corte Constitucional, Congreso de la República, objeciones presidenciales, sanción presidencial, contexto sociopolítico.

\section{ABSTRACT}

Approved the Draft Statutory Law of the Administration of Justice in the Special Jurisdiction for Peace, was submitted to the Constitutional Court for automatic control; declared constitutional, was sent to the Presidency of the Republic. President Iván Duque, challenged with six objections, sent to Congress, these were denied and the Project, sent to the Constitutional Court, ratified in its initial constitutionality. Finally, he was sanctioned by the President of the Republic, with his reiteration of the objections, as necessary, in the midst of an atmosphere of hostility from the National Government, the Attorney General, and the forces contrary to the Peace Accords, which put at risk the JEP. The existence and guarantee of the functioning of the JEP, the just and necessary implementation of the Peace Accords, the curb of the current threats to democracy and their existence, depend on the solidarity and massive support of the democratic forces that reverse the advance of the retarding forces, the authoritarianism and the neofascist currents, that under the flags of the «state of opinion", pretend to supplant the Constitutional State of law. The advances and obstacles of the JEP are analyzed in the current Colombian socio-political context. A critical and socio-legal approach is used, the historical and logical method, analysis and synthesis, primary and secondary sources and documentary analysis.

Keywords: Special Jurisdiction for Peace, Statutory Law of the Administration of Justice, Constitutional Court, Congress of the Republic, presidential objections, presidential sanction, sociopolitical context. 


\section{INTRODUCCIÓN}

El Proyecto de Ley Estatutaria de la Administración de Justicia en la Jurisdicción Especial para la Paz (Congreso, 2017) fue presentado el 1 de agosto de 2017 y tramitado por parte del Gobierno del presidente Juan Manuel Santos, en su primera etapa legislativa en cumplimiento e implementación del Acuerdo final para la terminación del conflicto y la construcción de una paz estable y duradera (Gobierno Nacional y FARC-EP, 2016), suscrito el 12 de noviembre de 2016 en La Habana (Cuba), ratificado el 24 de noviembre de 2016 en Bogotá por el presidente de la República, Juan Manuel Santos y el comandante de las FARC-EP, Rodrigo Londoño, refrendado por el Senado de la República, el 29 de noviembre y el 30 por la Cámara de Representantes, dándose inicio a su implementación (Matias Camargo, enero-junio 2018 y enero- junio 2017).

Por tratarse de una Ley Estatutaria en trámite, su proyecto, aprobado por el Congreso de la República, fue remitido el 14 de diciembre de 2017 por la Secretaría General del Senado a la Corte Constitucional, para la realización del control constitucional automático (arts.153 y 241.8 C.P.). Fue trasladado, el 18 de diciembre de 2017 al magistrado sustanciador Antonio José Lizarazo; el 12 de enero de 2018, la Corte asumió el control previo de constitucionalidad de dicho Proyecto de Ley, decretó las pruebas requeridas para verificar el cumplimiento de los requisitos constitucionales y legales de su trámite y el 15 de agosto la Sala Plena adoptó la decisión.

En ejercicio de sus facultades constitucionales, la Corte Constitucional expidió la Sentencia C-080/18 sobre Control automático de constitucionalidad del Proyecto de Ley Estatutaria número 08 de 2017 Senado, 016 de 2017 Cámara, «Estatutaria de la Administración de Justicia en la Jurisdicción Especial para la Paz», publicada el 19 de diciembre de 2018 (Corte Constitucional, 2018a y 2018b).

La citada Sentencia y el Proyecto de Ley Estatutaria de la Administración de Justicia en la Jurisdicción Especial para la Paz fueron aprobados por siete votos a favor, un voto en contra y un impedimento. ${ }^{1}$ Para la Jurisdicción Especial para la Paz, esta Sentencia constitucional, que aprobó el Proyecto de la Ley Estatutaria, regulador del funcionamiento de la JEP, «...es fundamental para el buen funcionamiento de la jurisdicción creada en el marco del Acuerdo de Paz firmado con las Farc, que garantiza los derechos de las víctimas y la seguridad jurídica de todos los comparecientes» (JEP, 2019, febrero 19).

1 Cristina Pardo Schlesinger y José Fernando Reyes Cuartas, sin salvamento de voto; Diana Fajardo Rivera, Alejandro Linares Cantillo, Antonio José Lizarazo y Alberto Rojas Ríos, con salvamento parcial de voto; Gloria Stella Ortiz Delgado con salvamento total de voto y Carlos Bernal Pulido, no votó por declararse impedido. 
Esta decisión afirmativa a favor de la JEP constituye un importante avance en el camino de la aplicación de la justicia transicional y la implementación de los Acuerdos de Paz. A la vez, representa un vivo ejemplo de las sombras y retrocesos, de los palos en la rueda, que ha tenido que soportar esta justa y democrática causa, de lo cual se tratará detenidamente en el recorrido de este texto. Este artículo es la continuación de uno anterior publicado en la revista Diálogos de Saberes nro. 50 del primer semestre de 2019 (Matias Camargo, enero-junio 2019).

La Jurisdicción Especial para la Paz (JEP) es un componente del Sistema Integral de Verdad, Justicia, Reparación y No Repetición (SIVJRNR), incluido en el Punto 5 del Acuerdo de $\mathrm{Paz}^{2}$ y en la Constitución Política de Colombia, por medio del Acto legislativo No. 1 de 2017. Además, está integrado por: (i) la Comisión para el Esclarecimiento de la Verdad, la Convivencia y la No Repetición; (ii) la Unidad de Búsqueda para Personas dadas por Desaparecidas; iv) las medidas de reparación integral para la construcción de paz y las garantías de no repetición, «...tiene como finalidad consolidar un escenario institucional transitorio o temporal suficiente y apropiado para satisfacer los derechos de las víctimas del conflicto armado y contribuir en la reconciliación nacional (JEP, 2019, junio 7)».

\section{EL PROYECTO DE APROBACIÓN DE LA LEY ESTATUTARIA DE LA JEP Y SU PRIMER RETORNO AL CONGRESO}

El Proyecto de Ley Estatutaria de la Administración de Justicia en la Jurisdicción Especial para la Paz y su correspondiente Sentencia constitucional positiva fueron radicados el 19 de diciembre de 2018 ante la Secretaría del Senado de la República, firmado por Ernesto Macías presidente del Senado el 31 de enero de 2019 y en esta fecha, enviado a la Cámara de Representantes. Alejandro Carlos Chacón, presidente de la Cámara de Representantes, «...dijo que no firmaría la ley estatutaria hasta tanto el presidente del Senado, Ernesto Macías, no haga las correcciones en el texto que fue avalado por la Corte Constitucional (elespectador.com, 2019, febrero 7)». Chacón afirmó que había omisiones, como las de «proteger los derechos de las víctimas; contribuir al logro de una paz estable y duradera; y adoptar decisiones que otorguen seguridad jurídica a quienes comparezcan ante la JEP» (2019, febrero 7).

Estos hechos dejaron en evidencia la demora y las irregularidades en el trámite en el Senado, presidido por Ernesto Macías del Centro Democrático, parti-

2 «5. Acuerdo sobre las Víctimas del Conflicto: “Sistema Integral de Verdad, Justicia, Reparación y No Repetición", incluyendo la Jurisdicción Especial para la Paz; y Compromiso sobre Derechos Humanos (Gobierno Nacional y FARC-EP, 2016, p. 124-191) ». 
do fundado y acaudillado por Álvaro Uribe, ex presidente de la República (2002-2010) y actual senador. El uribismo, actualmente en el gobierno, en la campaña electoral de 2017, prometió, según Fernando Londoño, que «el primer desafío del Centro Democrático será el de volver trizas ese maldito papel que llaman el acuerdo con las FARC (semana.com, 2017, agosto 5)». El ex presidente Uribe expresó por medio de su cuenta: «bueno que objeten la JEP, mejor eliminarla» (eltiempo.com, 2019, febrero 19). Finalmente, el Proyecto de Ley Estatutaria de la JEP, recibido en el Congreso el 19 de diciembre de 2018, fue firmado por el presidente de la Cámara y del Senado, y junto con la correspondiente Sentencia de constitucionalidad, radicado en la Presidencia de la República el 11 de febrero de 2019, para su sanción.

La Constitución Política de Colombia contiene los principios de primacía y superioridad. Es la «norma de normas» y es deber de los nacionales y extranjeros en Colombia acatarla, también las leyes, y respetar y obedecer a las autoridades (art. 4 y 95, C. P.). La Corte Constitucional es la garante de la guarda de la integridad y la supremacía de la Constitución y de la protección y garantía de los derechos fundamentales (art. 239-45, C. P.). En su condición de órgano supremo del control constitucional, tiene las funciones de revisar previamente los proyectos de leyes estatutarias (art. 153, C. P.) y decidir sobre su constitucionalidad (art. 241.8, C. P.). Los fallos que la Corte dicte en ejercicio del control jurisdiccional hacen tránsito a cosa juzgada constitucional y ninguna autoridad podrá reproducir el contenido material del acto jurídico declarado inexequible por razones de fondo, mientras subsistan en la Carta las disposiciones que sirvieron para hacer la confrontación entre la norma ordinaria y la Constitución (art. 243, C. P.).

El presidente de la República está facultado constitucionalmente para presentar objeciones, por razones de inconveniencia o de inconstitucionalidad al Proyecto de Ley Estatutaria, antes de su sanción, exclusivamente a los artículos declarados previamente exequibles, si en su criterio considera que son inconvenientes y remitirlos, para su trámite correspondiente al Congreso de la República. No está facultado para cuestionar los artículos declarados inexequibles por ninguna motivación, de conveniencia o de constitucionalidad, pretendiendo revivirlos (art. 166-168, C. P.).

\section{LAS IMPUGNACIONES DEL FISCAL GENERAL}

El fiscal general, Néstor Humberto Martínez, envió una carta al presidente Duque, con impugnaciones a la Ley Estatutaria de la JEP, después de expedida y conocida la Sentencia de exequibilidad de la Corte Constitucional. De tiempo atrás, el máximo intérprete y guardián de la Norma de Normas, ha sido 
claro y reiterativo sobre la naturaleza de sus decisiones: «La Corte Constitucional, en lo que hace a las normas sometidas a su examen, define, con la fuerza de la cosa juzgada constitucional, su exequibilidad o inexequibilidad, total o parcial, con efectos erga omnes y con carácter obligatorio general, oponible a todas las personas y a las autoridades públicas, sin excepción alguna (Corte Constitucional, 1998)».

Sobre las impugnaciones del fiscal general contra la Ley Estatutaria y la sentencia de constitucionalidad, Patricia Linares, presidenta de la JEP, manifestó su punto de vista en una rueda de prensa, enfatizando que no se puede desconocer la sentencia C-80 de 2018 de la Corte Constitucional y que lo que se está abriendo es un debate político, que ya se dio en el Congreso.
«Esta Corte -aseguró- ya hizo un examen detallado y exhaustivo de todas y cada una de las normas que fueron producidas en el Congreso de la Repú- blica, después de un amplio debate en el que participaron todos los partidos políticos, que consignaron sus acuerdos en esas normas que serán Ley de la República, una vez el señor Presidente sancione y promulgue dicha ley, como lo estableció la Corte Constitucional»...Sobre los temores del fiscal Martínez respecto a una eventual impunidad, la magistrada Linares mani- festó que «precisamente la Jurisdicción fue diseñada para garantizarles a las víctimas, al país y a la comunidad internacional que no habrá tal y que se sancionará a quienes hayan cometido crímenes de guerra y delitos de lesa humanidad en el marco del conflicto (2019)».

El Fiscal, con sus irregulares impugnaciones, fuera de sus competencias constitucionales, se propuso los objetivos de ambientar y justificar las objeciones presidenciales sobre la Ley Estatutaria y la sentencia de constitucionalidad; también, de atacar una vez más la JEP y los Acuerdos de Paz, con los cuales, desde el comienzo de sus negociaciones, ha estado en desacuerdo, haciendo fila con la oposición uribista y los enemigos de la Paz. El ex presidente de la Corte Constitucional, asesor del proceso de paz, del diseño de la JEP, y actual rector de la Universidad Externado de Colombia, Juan Carlos Henao, fue enfático en rechazar las objeciones presidenciales, afirmando «que aceptar la objeción por la dudosa vía de la inconveniencia sería una burda forma de desconocer el control de constitucionalidad ya realizado (Redacción Paz-El Tiempo, 2019)». En sentido semejante, el ex ministro de Justicia del gobierno de Juan Manuel Santos, Yesid Reyes, expresó que «ya la Corte dijo que las normas que menciona el Fiscal son contrarias a la Constitución (2019)» y objetar la Ley estatutaria de la JEP «no solo es contrario a la Constitución, sino al compromiso internacional que adquirió Colombia de respetar el Acuerdo de paz (2019)». 
El fiscal general está haciendo una invitación al presidente de la República a violar la Constitución Política, al impugnar la Ley Estatutaria de la JEP, y la Sentencia de exequibilidad, expedida por la Corte Constitucional, por supuestas «inconveniencias», cuando materialmente lo hace por inconstitucionalidad y pretende revivir artículos declarados inconstitucionales, lo cual está prohibido en la Constitución Política (art. 166-168).

\section{LAS OBJECIONES DEL PRESIDENTE DE LA REPÚBLICA IVÁN DUQUE}

El 10 de marzo de 2019, un mes después de su recepción, el presidente de la República Iván Duque, en alocución de televisión y radio, informó a los colombianos sus previstas objeciones al Proyecto de Ley Estatutaria de la JEP, y su decisión de radicar en el Congreso de la República, tan pronto fueran reanudadas las sesiones ordinarias, un proyecto de Acto Legislativo al Congreso de la República para reformarla (Duque, 2019).

En sus propias palabras, estas son las seis objeciones realizadas por el presidente Iván Duque, radicadas en la Secretaría General del Senado, el lunes 11 de marzo:

Para buscar una genuina Reparación el Gobierno objeta por inconveniente el artículo 7 de la ley estatutaria de la JEP porque no establece de manera clara la obligación principal de los victimarios de reparar integralmente a las víctimas. Los colombianos debemos tener claro la importancia de precisar que los victimarios deben adelantar una reparación material con sus bienes y activos que satisfaga a las víctimas. Es lo mínimo que Colombia espera.

Frente a una genuina verdad y una genuina No Repetición tenemos que objetar el inciso octavo del artículo 63 y el inciso tercero del literal j del artículo 79 de esta ley. El inciso octavo del artículo 63 es inconveniente para los colombianos porque no determina el alcance de la competencia atribuida al Alto Comisionado para la Paz para verificar la lista de quienes son reconocidos como miembros de los Grupos Armados que se sometan a un proceso de paz.

Quiero dejar claridad en este tema: la tarea de verificar las personas que participan de un proceso de paz debe seguir siendo competencia del Alto Comisionado para la Paz como representante del Presidente de la República. No es conveniente debilitar una atribución que por años ha tenido el Alto Comisionado para la Paz para evitar que delincuentes se oculten y ganen beneficios e impunidad, incorporándose a un proceso de paz por la puerta de atrás. 
El inciso tercero del literal j del artículo 79, por su parte, trata de la suspensión de las actuaciones de la Justicia ordinaria frente a personas cuyas acciones sean competencia de la JEP. Lo consideramos inconveniente ya que no precisa las diligencias judiciales que la Fiscalía debe abstenerse de realizar. Esto genera una situación que perjudica los intereses de las víctimas y desperdicia valiosos recursos investigativos de autoridades con experiencia y capacidad. Es conveniente definir con mayor precisión cuándo y bajo qué circunstancias las investigaciones contra personas sometidas a la JEP se suspenden en la Justicia ordinaria. Esta precisión es necesaria para evitar visos de impunidad y garantizar el derecho a la Verdad de las víctimas.

Se objeta, también, el parágrafo 2 del artículo 19 que trata de la renuncia a la acción penal frente a los crímenes de lesa humanidad, genocidio o crímenes de guerra en relación con quienes no son máximos responsables. Esa renuncia a la acción penal es inconveniente porque constituiría impunidad. El Estado no puede renunciar a perseguir a los responsables de los delitos de lesa humanidad sin haber agotado todos, todos los esfuerzos para encontrar la Justicia y la Verdad.

El artículo 150, referente a la extradición de personas por conductas posteriores a la firma del Acuerdo Final, es inconveniente debido a que no precisa lo que ya fue dicho en la ley de Procedimiento de la JEP cuando expresa que la Sección de Revisión del Tribunal de Paz no puede practicar pruebas. No hacer esa precisión afectaría gravemente la cooperación judicial de Colombia con otros países.

Objetamos, también, el artículo 153 por inconveniente, porque condiciona la extradición de otras personas al ofrecimiento de la verdad sin establecer ningún tipo de término ni oportunidad para hacerlo. Esto produce un incentivo perverso para el ingreso a la JEP de terceros bajo el ropaje de supuestos ofrecimientos de verdad. Esa ambigüedad puede ser utilizada para eludir responsabilidades ante la Justicia de otros Estados.

Colombianos, quise exponer de manera concisa las razones para nuestra objeción por inconveniencia en cada uno de los seis artículos. Cada una de nuestras observaciones busca la mejora y la corrección de la Justicia transicional para corregir estos aspectos y avanzar en la construcción de una paz que nos una. No podemos tenerle miedo a abordar estos cambios de manera constructiva y sin ánimo de polarizar (2019).

Sobre el proyecto de Acto Legislativo para reformar la Justicia transicional en tres puntos, el presidente Duque informó su plan: 
...quiero informarle a Colombia que existen al menos tres aspectos del actual ordenamiento constitucional sobre la Justicia transicional que debemos avanzar para ser modificados y que, estoy convencido, son necesarios para el país.

Para ello presentaremos al Congreso una reforma constitucional para modificar el acto legislativo 01 de 2017 que incluya estos tres puntos que mejoran la Jurisdicción Especial para la Paz. El primer punto es la exclusión de los delitos sexuales contra niños, niñas y adolescentes de la Justicia transicional. NADA, ninguna ideología, absolutamente nada, justifica la aberrante agresión a los más vulnerables de la sociedad. Los colombianos no debemos ahorrar ningún esfuerzo en la protección de los menores. En segundo lugar, esta iniciativa de reforma constitucional debe dejar claro que quien reincida en las actividades criminales perderá todos los beneficios.

Por último, este acto legislativo debe dejar claro que todas las conductas delictivas que se hayan iniciado antes del $1^{\circ}$ de diciembre de 2016 y que continúen ejecutándose después de esa fecha serán competencia de la Justicia ordinaria para asegurar los principios de Justicia y No Repetición (2019).

\section{LA PROCURADURÍA GENERAL DE LA NACIÓN}

El procurador general de la Nación, Fernando Carrillo, el 11 de marzo de 2019, expresó su rechazo a las objeciones del presidente Duque a la JEP. «"La Constitución de Colombia se respeta", dijo Carrillo, y las objeciones al proyecto de la ley estatutaria de la Jurisdicción Especial para la Paz (JEP) "abre un debate político inoportuno e inútil y desconoce el rol de la Corte Constitucional" (Procuraduría, 2019)». En el Boletín 48 de la Procuraduría se informa que el Procurador enumeró en 10 puntos $^{3}$ sus argumentos según los cuales las objeciones presidenciales a la JEP agudizan la fractura política que vive el país, ponen en alto riesgo la institucionalidad, generan un enfrentamiento innecesario entre los poderes, y abren espacio a la inseguridad jurídica. "A situaciones excepcionales, salidas excepcionales pero institucionales", sostuvo Carrillo Flórez al hacer un llamado al jefe de Estado a generar consensos y a no perder la oportunidad de ser el adalid de un gran pacto en el que participen las fuerzas vivas, las víctimas, los partidos, donde se "construya una agenda inmediata de ajustes y modificaciones a la JEP, si ello es necesario"» (Procuraduría, 2019).

3 Se pueden consultar en: https://www.procuraduria.gov.co/ portal/-La_Constitucion_ de_Colombia_se_respeta_Procurador_General.news (Procuraduría, 2019). 


\section{RESPALDO INTERNACIONAL A LA JEP}

La Organización de Naciones Unidas (ONU), el Consejo de Seguridad y el secretario general, Antonio Gutérres, han sido reiterativos en su respaldo a la JEP, a la necesidad de reglamentar y agilizar su funcionamiento y en consecuencia a la urgencia de sancionar la Ley Estatutaria. El 29 de marzo de 2019, el secretario general de las Naciones Unidas presentó ante el Consejo de Seguridad un Informe sobre la Misión de Verificación de la ONU en Colombia, donde manifestó su llamado al «Gobierno, al Congreso y a todas las entidades para que adopten rápidamente medidas para asegurar que la Ley Estatutaria se promulgue lo antes posible de conformidad con las disposiciones del Acuerdo de Paz (JEP, 2019a)». También, afirmó que la JEP «es el principal garante de los derechos de las víctimas a la verdad, la justicia, la reparación y la no repetición, y es también la expresión de las garantías jurídicas otorgadas a quienes, de buena fe, han dejado las armas con la verificación de las Naciones Unidas $(2019 a, b, c) » . "$

La Comisión Interamericana de Derechos Humanos se ha pronunciado reiterativamente.

La Comisión Interamericana de Derechos Humanos (CDIH), en su informe anual de 2018, instó al Estado colombiano a adoptar las medidas necesarias para avanzar en la definición y entrada en vigencia del marco normativo de la JEP.

El informe fue presentado por Esmeralda Arosemena de Troitiño, presidenta de la Comisión, quien añadió que la CIDH observa con preocupación que a más de dos años de la firma del Acuerdo de Paz y a un año de su entrada en funcionamiento, la JEP no cuenta con una Ley Estatutaria.

En dicho informe, dado a conocer este jueves 21 de marzo en Washington, la CIDH solicitó «respeto al principio de separación de poderes y a las decisiones de las autoridades que han intervenido en la aprobación y examen de constitucionalidad del proyecto de ley. Ello con el fin de avanzar en la implementación del Acuerdo de Paz y garantizar los derechos de las víctimas» (JEP, 2019d).

\section{TRÁMITE DE LAS OBJECIONES PRESIDENCIALES EN EL CONGRESO DE LA REPÚBLICA}

Después de las demoras intencionales, las objeciones presidenciales al Proyecto de Ley Estatutaria de la JEP, la secretaria jurídica de la Presidencia de la República, Clara María González, radicó el 11 de marzo las Objeciones 
gubernamentales por «inconveniencia» (Presidente de la República, 2019) ante la Secretaría General del Senado.

En relación con las objeciones recibidas, el presidente del Senado, Ernesto Macías, manifestó:

Respecto a los términos que tiene el Legislativo para estudiar las objeciones, el senador Macías afirmó: «Depende de la agilidad con que se estudie en las comisiones y en la plenaria, ya que se nos cruza con el Plan Nacional de Desarrollo, que tiene prioridad, porque es una ley que tiene término, de tal manera vamos a hacer que sea lo más rápido posible y sin correr».

Respecto a si las objeciones son o no un golpe a los acuerdos de paz, el legislador señaló: «El golpe se lo dieron a la Constitución cuando aprobaron esta normatividad (Ley Estatutaria de la JEP), de manera que hoy nosotros que no estuvimos de acuerdo con la JEP, que no la votamos, aceptamos hoy su existencia, pero hay que mirarla bien con detenimiento. Yo diría más allá de las objeciones, hay que mirar una reforma y sobre todo los controles para evitar la corrupción que ya se asomó allá en ese organismo» (Pinto, 2019).

El presidente de la Cámara de Representantes, Alejandro Chacón del Partido Liberal, realizó el 13 de marzo una consulta a la Corte Constitucional sobre la procedencia del trámite de las objeciones presidenciales. El 18 de marzo, se realizó en Bogotá y a nivel nacional una masiva movilización social, en respaldo al Proceso de Paz, a la JEP y de rechazo a las objeciones presidenciales al Proyecto de Ley Estatutaria. El diario bogotano ADN, de la Casa Editorial El Tiempo, del martes 19 de marzo, la registró:

Miles de defensores de la paz salieron ayer a las calles para apoyar el acuerdo firmado hace más de dos años entre el gobierno y las Farc y cuya implementación se encuentra en punto de incertidumbre por las objeciones parciales del presidente Iván Duque a la Ley Estatutaria para la Paz (JEP)...Las objeciones del presidente Duque a la paz han sido criticadas dentro y fuera del país. Organizaciones como la ONU, se han pronunciado en el sentido de que el gobierno colombiano debe respetar los acuerdos y darle trámite a la JEP (ADN, 2019a).

La Corte Constitucional respondió el 21 de marzo en el auto 123/19 la consulta del presidente de la Cámara sobre la pertinencia del trámite de las objeciones presidenciales al Proyecto de Ley Estatutaria de la JEP. Se declaró inhibida por unanimidad, manifestando que la revisión constitucional sobre las objeciones presidenciales solo se realizaría después de su debate en el Congreso. Conceptuó que las objeciones presidenciales deben ser tramitadas en una sola legislatura, hasta el 20 de junio de 2019, por ser el Proyecto de Ley Estatutaria, 
resultado del procedimiento especial o fast track (vía rápida) y el Congreso deberá remitirle el Proyecto de Ley resultado de las objeciones y su trámite. La Corte hará nueva revisión si hay hechos nuevos, «como una inconstitucionalidad sobreviniente que resulte del cambio de parámetro de valoración constitucional (ADN, 2019b; BBC, 2019)».

a. Cámara de Representantes. i. Comisión accidental. El presidente de la Cámara de Representantes nombró la Comisión Accidental para el análisis previo de las objeciones presidenciales al Proyecto de Ley Estatutaria de la JEP y su posterior traslado a la Plenaria.

El lunes 1 de abril, día en el cual estaba citada una Audiencia Pública por la Comisión accidental de la Cámara, el embajador de los Estados Unidos en Colombia, Kevin Whitaker, invitó a un desayuno privado en su residencia a un grupo de senadores y representantes a la Cámara, integrantes de las comisiones constitucionales especiales, encargadas de la presentación de las ponencias, en completa reserva y con pacto de no revelar el contenido del encuentro. Filtraciones iniciales dieron cuenta que «...algunos de los asistentes relataron que el diplomático manifestó su inquietud por el posible rechazo del Congreso a las objeciones, pues esto afectaría el tratado de extradición entre los dos países. De igual manera, se conoció que Whitaker también convocó a magistrados de la Corte Constitucional para hablar del tema, pero los togados se molestaron por considerar que se podría entender como una injerencia en temas nacionales y declinaron la invitación (Molano Jimeno, 2019)». La reunión del embajador de los Estados Unidos con los congresistas tuvo como fin evitar las derrotas de las objeciones presidenciales en el Congreso, en una clara intervención en los asuntos internos de Colombia.

La reunión se extendió por cerca de una hora y media, y según cinco de los seis asistentes, la conversación giró en torno a tres temas: la afectación que pueda tener la cooperación judicial entre ambos países y el caso Santrich; las represalias que podría tomar Estados Unidos y el malestar con el gobierno del ex presidente Juan Manuel Santos y con el manejo que le está dando el actual, el de Iván Duque, a la política antidrogas.

«Dijo que Santos, Jaramillo (Sergio) y (Humberto) De la Calle eran unos mentirosos, que habían engañado al gobierno de Barack Obama con el Acuerdo de Paz, que Santos siempre dijo que, con el Acuerdo, las Farc iban a entregar las rutas del narcotráfico y que iba a ser más fácil combatirlo, pero que pasó todo lo contrario», contó otro asistente. Y aunque algunos invitados dijeron que el senador de Cambio Radical, Antonio Zabaraín, le sugirió al embajador que saliera a micrófonos a decir abiertamente que su país se sentía engañado, Whitaker manifestó que no era conveniente, entre otras 
cosas, porque en el gobierno de Obama se había enviado a un delegado especial, Bernard Aronson, a acompañar la mesa de diálogos. De hecho, personas cercanas a los diálogos de La Habana comentaron que la fuerte postura del embajador se explica porque Obama siempre lo mantuvo relegado del proceso de paz, habida cuenta de su rechazo al mismo (Arboleda Zárate \& Molano Jimeno, 2019).

La Comisión accidental de la Cámara, el 1 de abril convocó una audiencia pública y realizó el correspondiente debate. Intervinieron, entre otros, el fiscal Néstor Humberto Martínez, ratificando sus impugnaciones; la presidenta de la JEP, Patricia Linares, cuestionando las objeciones presidenciales, y reiterando su pleno respaldo a la sentencia de la Corte Constitucional; representantes de la academia como Rodrigo Uprimny, investigador de Dejusticia y profesor de la Universidad Nacional de Colombia.

Por ser de interés, se reproduce parte del punto V, de la intervención de Rodrigo Uprimny.

\section{UN ACUERDO POLÍTICO AMPLIO EN TORNO A LA PAZ}

...quienes defendemos este Acuerdo Final de Paz insistimos que el Presidente se extralimitó en el uso de sus facultades para objetar el proyecto de ley estatutaria de la JEP, lo cual obstaculiza el funcionamiento ágil y certero de dicha jurisdicción, así como el cumplimiento de lo pactado. No comparto la argumentación del gobierno sobre el supuesto mandato popular, como lo he expresado en otras ocasiones ${ }^{4}$, pero no entraré en esa discusión. Por ahora, invito al Presidente a retirar las objeciones contra el PLE 08-16/2017, pues cuatro de ellas son inconstitucionales y las otras dos son innecesarias dado que pueden resolverse por medio de la interpretación de la jurisprudencia constitucional. Además, estas objeciones retrasan la adopción del marco jurídico completo que regule el funcionamiento de la JEP, lo cual implica que la jurisdicción tendrá que ejercer sus competencias con un marco jurídico más precario y suplir los vacíos jurídicos con interpretaciones más amplias. Más aún, esas objeciones no unen a los colombianos en torno a la paz, sino que han ampliado la distancia política entre uno y otro sector. En su lugar, el Presidente debería sancionar este proyecto de ley y presentar

4 Ver: Uprimny Yepes, Rodrigo. ¿Reformar el Acuerdo de Paz o ajustar su implementación?, 4 de agosto de 2018, El Espectador. Disponible en: https://www.elespectador. com/opinion/reformar-el-acuerdo- de-paz-o-ajustar-su-implementacion-columna804215; y ¿Mandato para reformar el acuerdo de paz? 12 de agosto de 2018. El Espectador. Disponible en: https:/ / www.elespectador.com/opinion/mandatopara-reformar-elacuerdo-de-paz-columna-805540 
proyectos de ley ordinaria para resolver las discrepancias que tenga en asuntos puntuales de la JEP. Si el Presidente Iván Duque no tiene esa grandeza, invito al Congreso de la República a que construya un acuerdo político amplio para rechazar las cuatro objeciones que claramente son inconstitucionales, porque el Presidente obró por fuera de sus facultades, y presentar proposiciones que respondan a las objeciones 4 y 6 . Ello podría generar una votación masiva de los congresistas y resolver en el corto plazo esta discusión. Estas vías garantizan la cosa juzgada constitucional, la intangibilidad de los fallos constitucionales y el principio de independencia constitucional; y, al mismo tiempo, facilitarían la búsqueda de consensos políticos amplios que pacifiquen la paz ${ }^{5}$ (Uprimny, 2019).

Las seis objeciones del presidente Duque al Proyecto de Ley Estatutaria de la JEP fueron rechazadas por mayoría en la Comisión accidental de la Cámara. Se constituyó una nueva correlación de fuerzas en la Cámara, de partidarios de la paz, de la JEP, de la Ley Estatutaria, de la Sentencia de la Corte Constitucional y de su acatamiento pleno. Del lado del presidente Duque, partidos oficialmente declarados de gobierno, como el Centro Democrático, del presidente Duque, el Partido Conservador de la vicepresidenta Martha Lucía Ramírez y sectores cristianos. En el polo opuesto, el Partido de la U y el Partido Liberal, formalmente declarados partidos de gobierno; Cambio Radical y el Partido Verde, declarados partidos independientes; y los partidos y movimientos de oposición, expresamente declarados, el Polo Democrático Alternativo, Colombia Humana, Decentes y el Partido FARC, este último declarándose impedido para votar, por estar directamente relacionado con la JEP, un resultado de los Acuerdos de Paz con ellos.

La coalición mayoritaria presentó un extenso y argumentado Informe ${ }^{6}$ de rechazo a las objeciones presidenciales e insistencia en el texto aprobado por la Corte Constitucional, firmado por cinco de los siete representantes a la Cámara, integrantes de la Comisión accidental. ${ }^{7}$ El Informe de la coalición mayorita-

5 Comisión de Superación de la violencia. Reyes, A. (Director), Correa, D. (Ed.). Pacificar la Paz: Lo que no se ha negociado en los acuerdos de paz. Bogotá: 1992.

6 Ver texto completo: Informe de rechazo de las objeciones presidenciales al proyecto de ley estatutaria 008/17 Senado- 016/17 Cámara «Estatutaria de la Administración de Justicia en la Jurisdicción Especial para la Paz» e insistencia en el texto aprobado por la Corte Constitucional. http:/ / static.iris.net.co/semana/upload/documents/71c64b_a4e7 dc1d4d184723a35e86b05b9ef030.pdf (Cámara, 2019).

7 Carlos Ardila Espinosa del Partido Liberal; John Jairo Cárdenas Morán, del Partido de La U; Juanita Goebertus Estrada de Alianza Verde; José Daniel López Jiménez de Cambio Radical y David Rocero Mayorga de la Coalición Decentes. Los representantes Álvaro Hernán Prada del Centro Democrático y Jaime Felipe Lozada del Partido Conservador, presentaron Informe de respaldo a las objeciones presidenciales. 
ria está dividido en cuatro partes, las conclusiones y una proposición. La primera parte cuestiona las afirmaciones del presidente Duque sobre su búsqueda de la unión los colombianos y se insiste en la defensa del texto original del Proyecto de Ley Estatutaria de la JEP y de la Sentencia de exequibilidad de la Corte Constitucional. Las objeciones son de carácter constitucional sobre una cosa juzgada y no de inconveniencias, como lo afirma el presidente Duque. La segunda parte hace referencia a los procedimientos seguidos para la elaboración del Informe y se expone su marco jurídico. La tercera parte sustenta por qué las objeciones presidenciales no cumplen con la carga argumentativa de los presuntos supuestos económicos, políticos o sociales y se hace referencia a las intervenciones del fiscal general, Néstor Humberto Martínez y de la presidenta de la JEP, Patricia Linares. La cuarta parte reitera que no había razones válidas para objetar asuntos sobre los cuales ya se había pronunciado la Corte Constitucional.

Por considerarla de interés y como una síntesis, se reproduce literalmente la Conclusión y la Proposición del Informe de rechazo a las objeciones presidenciales e insistencia en el texto aprobado por la Corte Constitucional.

\section{CONCLUSIÓN}

De lo expuesto tenemos que las objeciones presidenciales no se refieren a asuntos de inconveniencia, sino que buscan revivir disposiciones inexequibles; debatir interpretaciones hechas por la Corte Constitucional; y desconocer el carácter definitivo del reconocimiento de la exequibilidad de varias de las normas objetadas. Por tanto, el señor Presidente se equivoca en el procedimiento para modificar disposiciones incluidas dentro del PLE, que ya han sido objeto de estudio por parte de la Corte Constitucional, vulnerando el principio de cosa juzgada constitucional y de paso la supremacía de la Constitución.

El gobierno del Presidente IVÁN DUQUE MÁRQUEZ ha asumido una posición que dificulta la implementación del Acuerdo Final para la Terminación del Conflicto y la Construcción de una Paz Estable y Duradera (en adelante Acuerdo Final) y es importante destacar que debemos abogar por darle cumplimiento al Acto Legislativo 02 de 2016 que señala que: [1]as instituciones y autoridades del Estado tienen la obligación de cumplir de buena fe con lo establecido en el Acuerdo Final. En consecuencia, las actuaciones de todos los órganos y autoridades del Estado, los desarrollos normativos del Acuerdo Final y su interpretación y aplicación deberán guardar coherencia e integralidad con lo acordado, preservando los contenidos, los compromisos, el espíritu y los principios del Acuerdo Final». (Negrillas del texto original). Ante esta situación, resulta de la mayor importancia la 
defensa de la institucionalidad y de la supremacía de la Constitución. Es por ello que el rol de la Corte Constitucional debe prevalecer en asuntos donde estén en juego decisiones sobre aspectos constitucionales, tanto por el mandato del artículo 4 de la Constitución, como por el respeto irrestricto a la separación de poderes, el sistema de pesos y contrapesos, y la colaboración armónica entre las Ramas del Poder Público.

El ataque a la norma estatutaria de la Jurisdicción Especial para la Paz impide el pleno avance de la JEP y a su vez, pone en riesgo la garantía de los derechos de las víctimas y la seguridad jurídica de quienes se someten a ella. Es claro que, de ninguna manera, esta situación corresponde a un cumplimiento de buena fe con lo acordado y se presenta más como una estrategia retórica que no ofrece alternativas para superar las preocupaciones genuinas que existen respecto al funcionamiento de la JEP. Por ejemplo, el señor Presidente hace alusión constantemente al rechazo frente al juzgamiento en la JEP de los delitos cometidos en el conflicto contra menores; sin embargo, en las objeciones no se refiere al asunto, lo que muestra que su estrategia discursiva busca disociar y apelar al rechazo que genera en todos nosotros esa clase de delitos, pero no ofrece opciones viables y razonables para lograr una justicia efectiva para ese tipo de casos, desconociendo también, que la JEP justamente busca impartir justicia respecto a ese tipo de delitos considerados de la mayor gravedad.

Todo lo anterior, trae como consecuencia ineludible que la mejor vía para avanzar en la implementación del Acuerdo Final, conforme al AL 2/2017, y respetar la separación de poderes, es rechazar las objeciones presidenciales e insistir en el PLE objetado, que fue debatido en democracia y surtió el procedimiento constitucional correspondiente (Cámara, 2019).

A continuación, se reproduce literalmente la Proposición.

\section{PROPOSICIÓN}

En mérito de lo presentado en el informe, le solicitamos a la Plenaria de la Cámara de Representantes: 1. Rechazar* las objeciones presentadas por el señor Presidente IVÁN DUQUE MÁRQUEZ e INSISTIR* en el PLE 008/ Senado- 016/17 Cámara «Estatutaria de la Administración de Justicia en la Jurisdicción Especial para la Paz» en los términos aprobados por la Corte Constitucional; y 2. Una vez finalizado el trámite en la Corporación, a través de la Secretaría de Cámara de Representantes, remitir a la Corte Constitucional para que en cumplimiento de los artículos 241(8) y 153 de la Constitución, y 1 del Acto Legislativo 01 de 2016 decida de manera definitiva sobre la constitucionalidad del mismo respecto al procedimiento de for- 
mación y al contenido de los artículos objetados (Cámara, 2019). *Negrillas del texto original.

ii. Plenaria de la Cámara de Representantes. En la plenaria de la Cámara de Representantes, el 8 de abril, se realizó el correspondiente debate de las objeciones presidenciales al Proyecto de Ley Estatutaria de la JEP, con una votación de 111 votos en contra y 44 a favor. En la sesión plenaria, se consolidó la correlación de fuerzas que se había constituido en la Comisión accidental, con partidarios de la paz, de la JEP, de la Ley Estatutaria, de la Sentencia de la Corte Constitucional y de su acatamiento pleno, confirmándose el debilitamiento de las fuerzas oficialistas y de la gobernabilidad del presidente Duque. La coalición mayoritaria confirmó el Informe ${ }^{8}$, anteriormente analizado, y en esta oportunidad, respaldado por 144 votos favorables al rechazo de las objeciones presidenciales e insistencia en el texto aprobado por la Corte Constitucional y 44 a favor de las objeciones presidenciales.

b. Senado. i. Comisión accidental del Senado. El presidente del Senado, Ernesto Macías del Centro Democrático, nombró la Comisión accidental para el análisis previo de las objeciones presidenciales al Proyecto de Ley Estatutaria de la JEP y su posterior traslado a la Plenaria para su discusión. ${ }^{9}$

El martes 9 de abril, los senadores Iván Marulanda de la Alianza Verde y Alberto Castilla Castilla, del Polo Democrático, radicaron ponencia negativa en la Secretaría General del Senado, solicitando a la plenaria, rechazar las objeciones presidenciales al Proyecto de Ley Estatutaria de la JEP. Las objeciones presidenciales no son por inconveniencia, son cuestionamientos sobre los cuales la Corte Constitucional ya se pronunció, plantean los ponentes de la minoría en la Comisión accidental, nombrada por Ernesto Macías (eltiempo.com, 2019, abril 9).

El jueves 11 de abril, se realizó una audiencia pública convocada por la Comisión accidental del Senado, para el análisis de las objeciones presidenciales al

8 Informe de rechazo de las objeciones presidenciales al proyecto de ley estatutaria 008/ 17 Senado- 016/17 Cámara «Estatutaria de la Administración de Justicia en la Jurisdicción Especial para la Paz» e insistencia en el texto aprobado por la Corte Constitucional (Cámara, 2019).

9 Comisión integrada por Paloma Valencia, del Centro Democrático; Julián Bedoya, del Partido Liberal; David Barguil, del Partido Conservador; Jonathan Tamayo, del movimiento ASI (uribista); John Milton Rodríguez, de Colombia Justa y Libres; Iván Marulanda, de la Alianza Verde y Alberto Castilla, del Partido Polo Democrático. El senador del Partido de la U, José David Name, quien renunció a participar de este grupo de trabajo, y en carta dirigida al Presidente del Senado, expuso que su bancada votará en bloque como lo hizo en la Cámara, donde rechazó las objeciones (Medina, 2019). 
Proyecto de Ley Estatutaria de la JEP (Medina, 2019). El fiscal dijo que en la Ley Estatutaria de la JEP se había colado un «articulejo» que impedía la extradición de narcotraficantes.

Ante esto, el jefe del ente acusador reveló que el gobierno de los Estados Unidos está muy preocupado por los alcances de ese artículo y el futuro que pueda tener en el Senado, cuando la corporación se pronuncie a fondo sobre las objeciones presidenciales. El Fiscal Martínez dijo que está indagando quién fue el autor de ese artículo, que no dudó en calificar de «muy dudosa inspiración». Durante su exposición reconoció que esa disposición se le había pasado a la Fiscalía en el estudio que le hizo a la ley estatutaria de la JEP (Senado, 2019).

La Comisión accidental del Senado hizo el correspondiente debate y sometió a votación interna sus textos, quedando aprobadas por mayoría las objeciones presidenciales. En la plenaria del Senado del treinta de abril, se realizó la correspondiente votación de las objeciones presidenciales, rechazándolas, con 47 votos en contra y 34 a favor. El presidente del Senado, Ernesto Macías del Centro Democrático, declaró que no había decisión; según él, el Senado tiene un total de 108 integrantes: catorce estaban impedidos de votar, quedando 94 habilitados, y para la aprobación, se necesitan la mayoría calificada, es decir, 48 votos favorables, la mitad más uno de los senadores habilitados. Por su parte, los opositores, afirmaron que «La totalidad (del Senado) recae sobre 106. Pero a este universo se le debe restar los 14 impedimentos, quedando así solo 92 senadores aptos para votar. Por tanto, 47 votos es la mayoría absoluta (eltiempo.com, 2019, mayo 1)».

La diferencia, relacionada con los integrantes, está en que el presidente del Senado cuenta la totalidad, incluyendo a una senadora privada de la libertad, Aida Merlano, sin poderse posesionar e Iván Márquez, quien no se ha posesionado de su curul. Los opositores sostienen que por razones materiales los dos senadores no posesionados no deben contarse como habilitados; estos son 106, porque ellos no podían estar presentes en el momento de la votación, aunque formalmente Iván Márquez sea poseedor de su curul y Aida Merlano por haberla perdido en decisión del Consejo de Estado, sin remplazo.

El Senado continuó en la sesión plenaria del 1 de mayo el debate sobre las objeciones al Proyecto de Ley Estatutaria de la JEP irregularmente. Al momento de dar por terminada la sesión del día anterior, no se anunció el debate, como está legalmente establecido para su continuidad, y no podía continuarse en esta sesión. Al abrirse el registro para intentar la segunda e irregular votación, las mayorías opositoras se retiraron del Congreso y el presidente del Senado realizó la votación, con un quorum deliberatario (no decisorio), en una 
expresa violación de los procedimientos constitucionales y legales establecidos, con una votación viciada de nulidad de 33 a favor y 2 en contra de las objeciones. Se declaró que en virtud de los votos obtenidos, no hubo decisión de ninguna naturaleza. Finalmente, se aprobó el envío a la Corte Constitucional, como esta lo había establecido, del Proyecto de Ley estatutaria de la JEP, con las objeciones presidenciales y las decisiones del Senado y la Cámara.

En síntesis, las objeciones presidenciales al Proyecto de la Ley Estatutaria de la JEP y a la sentencia de exequibilidad de la Corte Constitucional fueron rechazadas, con la mayoría calificada de cuarenta y siete votos por el NO y con la minoría de treinta y cuatro votos por el SÍ de los senadores habilitados constitucional y legalmente. En la Cámara de Representantes, fueron rechazadas, con la mayoría absoluta de 144 votos por el NO y con la minoría de 44 votos por el Sí de los representantes habilitados constitucional y legalmente, quedando rechazadas por el Congreso de la República.

\section{RETORNO A LA CORTE CONSTITUCIONAL Y SU DECISIÓN FINAL}

El Proyecto de Ley estatutaria de la JEP, las objeciones presidenciales y las decisiones del Senado y la Cámara de Representantes fueron radicados en la Secretaría de la Corte Constitucional, el 7 de mayo de 2019. La Corte Constitucional nombró el 8 de mayo a Antonio José Lizarazo como magistrado sustanciador, para la revisión final de las objeciones presidenciales al Proyecto de Ley Estatutaria de la JEP y las decisiones de la Cámara y el Senado, actuando como órgano de cierre del control previo, automático y único de las leyes estatutarias.

La Corte Constitucional, el 10 de mayo, radicó una petición al secretario general del Senado, para que le informara, en un término de tres días, qué senadores estaban ausentes al momento de las votaciones de las objeciones presidenciales y las causales de su ausencia, «indicando, respecto de cada uno de ellos, las razones de excusa invocadas [...] o las razones de su ausencia, tales como: i. no haber tomado posesión del cargo; ii. incapacidad física [...] comprobada [...]; iii. suspensión de la condicional congresional; iv. impedimento o recusación aceptada; v. condena por delito [...] o [acción] contra los mecanismos de participación democrática» [sic], etc. (Noticias 1, 14 de mayo de 2019).

El 29 de mayo la Corte Constitucional, con ponencia del magistrado Antonio José Lizarazo, siete votos a favor, uno en contra, del magistrado Luis Guillermo Guerrero y uno impedido, Carlos Bernal, declaró negadas las objeciones pre- 
sidenciales al Proyecto de la Ley Estatutaria de la JEP, de acuerdo con los resultados negativos de la Cámara de Representantes y del Senado y lo trasladó, con la correspondiente Sentencia de constitucionalidad a la Presidencia de la República, para su sanción presidencial. El 30 de mayo, un día después de su expedición, la Corte radicó su decisión final en la Presidencia de la República. Para la Corte Constitucional, 92 senadores estaban habilitados para votar, 14 con impedimentos legalmente declarados, dos senadores sin posesionarse; en consecuencia, los 47 votos contrarios a las objeciones presidenciales, en la sesión del 30 de abril, constituyeron la mitad más uno de los habilitados, cumpliéndose lo establecido en la Constitución Política. Declaró la negación del Senado y la de la Cámara de Representantes y al no haberse introducido ningún cambio al Proyecto de Ley Estatutaria de la JEP y haber sido previamente declarada constitucional, ordena su traslado al presidente de la República, para su sanción, posterior promulgación y entrada en vigencia de la Ley Estatutaria de la JEP. La Corte Constitucional consideró que no hubo ningún cambio en el contenido del Proyecto de Ley Estatutaria de la JEP; no era procedente discutir si el presidente de la República estaba facultado o no para presentar las objeciones que presentó, si eran por «conveniencia» o si eran por constitucionalidad.

\section{SANCIÓN PRESIDENCIAL DE DUQUE Y ENVÍO AL CONGRESO. DEBATES SOBRE ESTOS TRES HECHOS ANTERIORES}

El presidente de la República, Iván Duque, reaccionó agresivamente a la decisión de la Corte Constitucional. Expresó acatarla, dejando indicios de querer burlarla; afirma que los puntos objetados eran necesarios y pidió a los colombianos «reflexionar sobre las herramientas que quedaron abiertas (con esta decisión de la Corte) para corregir las cosas que no están saliendo bien (...) Acato la decisión que toma la Corte Constitucional como colombiano y defensor de la legalidad, pero nunca dejaré de defender los principios de una paz con justicia (elespectador.com, 2019, mayo 29)». En alocución nacional de televisión y radio, dijo que sancionará la Ley Estatutaria de la JEP, y al tiempo, reiteró que tiene la razón en las objeciones, realizadas con criterios «patrióticos» y recurrirá a todos los medios para reformarla.

El jueves 30 de mayo, ante un grupo de empresarios, que le ofrecieron su respaldo en la Cámara de Comercio de Bogotá, Duque manifestó que está convencido de la importancia de sus dudas expresadas alrededor del proyecto de ley Estatutaria de la JEP y dijo: «Presentamos esas objeciones, y como lo dije ayer (miércoles 29), me someto a la decisión del Congreso o a la de la Corte, pero también quiero que quede claro que si las tuviera que volver a presentar lo haría, porque los principios no se pueden dejar de defender (eltiempo.com, 2019, mayo 30)». 
Se trata de la fidelidad a los dictados de su partido el Centro Democrático y de su jefe político Álvaro Uribe, quien ha expresado reiteradamente que la JEP debe derogarse (Uribe, 2019, febrero 19) ${ }^{10}$ y en consecuencia se propone desprestigiarla, también a la Corte Constitucional y a sus decisiones ponerlas en entredicho permanentemente, desconociendo el Estado constitucional de derecho y elevando su teoría del «estado de opinión», como «forma superior del estado de derecho» (eltiempo.com, 2019, junio 17). La Oficina de Comunicaciones del ex presidente Álvaro Uribe, en carta dirigida a la editora de la revista Semana, fechada el 15 de junio de 2019, con seis «precisiones», en la número 2 expresa que: «En diálogo con La W el ex presidente y senador Álvaro Uribe, explicó que el Estado de opinión no va contra el Estado de derecho, sino que es su expresión superior» (Oficina de Comunicaciones, 2019, junio 15).

La «Frase de la semana» de la revista Semana del 2 de junio es del presidente Duque, quien en respuesta a quienes consideraron que había sido un error político, reitera sus propósitos, dijo: «No fue una derrota ni un desgaste presentar las objeciones. A uno nunca lo derrotan por defender los principios (2019, junio 2, p. 17)». La JEP, el Congreso de la República y la Corte Constitucional desconocieron sus principios de «una paz con justicia, una paz en la que todos creamos. Así seguiré procediendo todos los días de mi vida (Semana, 2019, junio 2, p. 27)». Ha perdido una batalla (aunque lo desconozca), pero no la guerra contra la JEP y los Acuerdos de Paz, sus enemigos principales. Dice acatar las decisiones de la Corte Constitucional y del Congreso de la República y al mismo tiempo adelanta una campaña para desconocerlas. Se trata de desconocer por la vía del atajo la cosa juzgada constitucional sobre el proyecto de ley Estatutaria de la JEP y de revivir artículos declarados inconstitucionales, en contravía de la Constitución Política (art. 243) (Congreso, 2019).

Finalmente, después de muchas idas y venidas, vueltas y revueltas, el presidente Duque sancionó, en privado y en contra de sus deseos, la Ley 1957 del 6 de junio de 2019, Estatutaria de la Administración de Justicia en la Jurisdicción Especial para la Paz (República de Colombia, 2019, junio 6). Lo hizo por obligación, determinado por la fuerza coercitiva de la Constitución Política y las Leyes de la República. Según las palabras de Álvaro Uribe, porque «...a él no le queda más camino que sancionar esa ley, pero eso no es óbice para no intentar reformas y reformas profundas (Pérez, 2019, junio 6)». El senador Iván

10 «El ex presidente Álvaro Uribe sorprendió este lunes en la noche cuando, a través de su cuenta de Twitter, dijo: 'bueno que objeten la JEP, mejor eliminarla'. Lo hizo en relación con la polémica que ha suscitado en los últimos días el proyecto de ley estatutaria de la JEP (Jurisdicción Especial para la Paz), que espera la firma del presidente Iván Duque...Uribe ha hecho énfasis en que esta no es una postura nueva, sino que es algo en lo que su partido ha insistido desde hace rato» (eltiempo.com, 2019, febrero19). 
Cepeda del Polo Democrático, en sentido contrario, expresó: «estamos pasando de las objeciones a las obsesiones. Ya el Congreso se pronunció, ya lo ha hecho la Corte Constitucional y ahora se quiere que el país invierta otro año o dos años en discutir nuevas reformas al proceso de paz, pero ya la opinión pública está saturada con este asunto...y ya se surtieron los procedimientos para que la JEP funcione como debe ser. Ya dejemos las obsesiones ex presidente Uribe (Pérez, 2019, junio, 6)».

No acababan de secarse las firmas de la sanción presidencial a la Ley Estatutaria de la JEP, cuando Álvaro Uribe arreció sus ataques y declaró que presentaría con su bancada parlamentaria del Centro Democrático reformas constitucionales con el objetivo de eliminarla, confiando en el respaldo del presidente Duque, después de 20 de julio, en el inicio del segundo periodo legislativo de 2019-2020. Reiteró enfáticamente: «En el partido consideramos que el país debería repensar el tema de la JEP, porque no nos podemos quedar en esta interinidad de 15 o 20 años dependiendo de ella. Yo creo que se debería analizar el tema de sustituir a la JEP por una sala especializada en la Corte Suprema de Justicia (Caracol Radio, 2019, junio, 6)».

La Presidencia de la JEP expidió un Comunicado, anunciando la sanción de la Ley Estatutaria:

$\cdots$

A partir de esta decisión, la JEP cuenta con todos los instrumentos constitucionales y legales para aplicar criterios y concentrar así el ejercicio de la acción penal respecto a quienes tuvieron participación determinante en los hechos más graves y representativos del conflicto armado. Además, la Ley Estatutaria fija parámetros claros para la atención de las víctimas y la materialización de sus derechos. Asimismo, se garantizan plenamente los derechos de las víctimas a lo largo de todos los procesos en la JEP. Es importante destacar que la Ley Estatutaria también afianza la seguridad jurídica para 11.805 comparecientes que están sometidos a este modelo de justicia. De otra parte, la Ley Estatutaria deja claro que la JEP atenderá con un enfoque diferencial los crímenes de violencia sexual y de género ocurridos en el conflicto armado.

«Nos da tranquilidad que con la Ley Estatutaria se despeja el camino para que la JEP cuente con sus normas completas» reiteró Patricia Linares, presidenta de la JEP.

Con la sanción de la Ley Estatutaria se completa el marco legal de la JEP que está compuesto también por el Acto Legislativo 01 de 2017, la Ley 1820 de 2016 y la Ley 1922 de 2018 (6 de junio). 
Al tiempo, Álvaro Uribe respalda y promueve un Referendo, que se propone reformas constitucionales a la Justicia, eliminar la JEP, la Corte Constitucional y remplazarlas por una sola Corte y reducir el Congreso a su mínima expresión. Los promotores del Referendo, seguidores del uribismo, encabezados por el periodista Herbin Hoyos, ya lo radicaron en la Registraduría General y recibieron los formularios para recoger las firmas necesarias, para iniciar su trámite.

En entrevistas radiales (La W y Blu Radio) en los últimos días, Uribe expresó su apoyo a varios puntos de la propuesta de Hoyos, como eliminar la JEP y sacar de sus cargos a los magistrados de las altas cortes. Uribe, a propósito de la iniciativa de Hoyos, se manifestó en favor de eliminar también la Corte Constitucional y crear una sola alta corte en el país.

«Yo estoy de acuerdo con varios puntos de ese referendo, lo firmaría y los apoyaría», dijo Uribe en las entrevistas. No obstante recalcó que ni él, ni el Centro Democrático, están promoviendo esta medida y que nació como una iniciativa popular (eltiempo.com (2019, junio, 18).

El presidente Duque «dijo, que "el gobierno es respetuoso de iniciativas ciudadanas", y aunque no fue expreso en su apoyo a ese referendo, sí se mostró tolerante con la iniciativa» (eltiempo.com, 2019, junio, 18). Uribe considera que el citado referendo hace parte de lo que él llama el «estado de opinión» retomando esta teoría que ya había planteado en su doble periodo presidencial de 2002-2010 y particularmente agitada en periodos electorales, como el de su reelección para el segundo periodo de 2006-2010, después de haber promovido en su propio beneficio la reforma del texto original de la Constitución Política de 1991, que la prohibía. Reforma irregular, viciada de nulidad, proceso que se conoció como la «yidispolítica», por haberla logrado sobornando a la senadora Yidis Medina y al senador Teodolindo Avendaño, quienes fueron penalmente condenados por cohecho, y sus coautores, los ministros de Trabajo Diego Palacios; del Interior Sabas Pretelt y el secretario de la Presidencia de la República, Alberto Velásquez (eltiempo.com, 2015, abril 6).

El senador Roy Barreras presentó una constancia, en la última sesión del periodo legislativo 2018-2019, de la Comisión Primera del Senado, realizada el 18 de junio de 2019. Hizo un balance negativo de la indebida implementación de los Acuerdos de Paz, por parte del Gobierno del presidente Duque, poniendo el énfasis en la sistemática ola de terror y de asesinatos de los guerrilleros desmovilizados y de los líderes sociales, señalando que no se ha cumplido el compromiso de garantizar su derecho a la vida y la obligación del Estado de garantizarle la vida a todos los colombianos. Le dio la razón al negociador en La Habana, Sergio Jaramillo, por sus afirmaciones en el mismo sentido de no 
estarse implementado adecuadamente los Acuerdos de Paz, poniendo como ejemplos, el desarrollo rural integral, la reforma política, el compromiso institucional con las víctimas de reconocerles diez y seis curules en el Congreso que fueron negadas por el partido de gobierno (Barreras, junio 18).

En la segunda parte de su constancia, el senador Barreras hizo un análisis de la teoría de «estado de opinión», propuesta por el senador Uribe y su partido el Centro Democrático, que calificó de origen nazi-fascista.

El «Estado de opinión»... tiene que ver con las raíces profundas de la filosofía jurídica de Carl Schmitth ${ }^{11}$ y el origen del nazismo y del fascismo, la destrucción de las instituciones. Ese referendo que se propone para acabar con las Cortes y con el Congreso es una amenaza para la democracia y está revestido de populismo y de falsedad. En el plebiscito por el «NO» se les dijo a los padres de familia que marcharon de buena fe, que quien apoyaba la paz, iba a poner en riesgo sus hijos por la ideología de género. Ahora pretenden repetir... (Minuto 7:28 inaudible, ruido extraño) que el fallo de la Corte Constitucional, le entregó los parques a los narcotraficantes (inaudible) eso es manipulación de las emociones.

Se levantan esas banderas con fines electorales en octubre, ${ }^{12}$ se invita a marchar contra las Cortes y de paso hacer un referendo para cerrarlas. Solamente los regímenes autocráticos pretenden que se cierren las Cortes, que se recorte el Congreso, que se recorte la democracia y que un gran caudillo, un gran Mesías, gobierne los destinos de todos. Aquí se trata, no solo de defender la Paz, sino de defender la democracia y las instituciones. El Estado de opinión populista no pasará, mientras haya quienes defiendan la democracia colombiana. Esa es mi constancia, señor presidente (junio, 18).

\section{EL AUTORITARISMO Y LA MAYOR PRECARIZACIÓN DE LA DEMOCRACIA}

Los hechos aquí analizados son parte importante de los impactos negativos del nuevo contexto político social, iniciado con el triunfo del Centro Democrático en las elecciones de Iván Duque, como presidente de la República, del 7 de agosto de 2018 al 7 de agosto de 2022, y de Luis Ernesto Macías, como presidente del Congreso de la República, para el primer periodo legislativo, del 20

11 Ver: Donato \& González (2011). Por su parte el jurista y filósofo del derecho Luis Villar Borda, califica a Carl Schmitth, como «el jurista de Adolfo Hitler» (Villar, 2009, p. 137).

12 Elecciones de gobernadores, alcaldes, asambleas, concejos y juntas administradoras locales. 
de julio de 2018 al 20 de julio de 2019 (Matias Camargo, 2019, junio 30). La situación actual de la JEP pareciera ser la «crónica de una muerte anunciada» por Álvaro Uribe, su partido Centro Democrático y el presidente colombiano Iván Duque, acompañado por el ex fiscal general Néstor Humberto Martínez, a la cabeza de las fuerzas retardatarias y guerreristas, en la escalada de una ofensiva nacional contra los Acuerdos de Paz con las FARC.

El triunfo espúreo del NO, en el Plebiscito sobre la Paz, del 2 de octubre de 2016, con base en la tergiversación de su contenido, una campaña de mentiras y de terror, «tuvo un resultado negativo con el $50.21 \%, 6.431 .376$ votos por el NO y un $49.79 \%, 6.377 .482$ votos por el SÍ, una minúscula diferencia del $0.42 \%$, 53.894 votos. No obstante lo anterior, el ganador fue el abstencionismo, de 34.899.945 de ciudadanos habilitados para votar, 21.833.898 de ciudadanos no lo hicieron $(62.57 \%)$ y solo hubo 13.066 .047 de ciudadanos participantes (37.43\%)» (Matias Camargo, 2017, enero-junio, p.28-29).

Este triunfo pírrico, la campaña y el Programa electoral de gobierno de Duque no son argumentos válidos para desmontar los Acuerdos de Paz. Es una flagrante violación del orden constitucional y legal vigente. Se trata de un zarpazo con el cual se pretende remplazar el Estado Constitucional de derecho por el «estado de opinión», elevado a la suprema categoría de «forma superior del Estado de derecho», promovido por Álvaro Uribe y el Centro Democrático, de tiempo atrás. El 28 de mayo de 2009, el entonces presidente Álvaro Uribe en la inauguración del «Foro de Inversiones y Cooperación Empresarial Hispano-Colombiano», expresó: « ¿Por qué mi interés por la opinión pública? Porque finalmente en este Estado, donde se vive esa etapa superior del Estado de Derecho que es el Estado de opinión, lo único sostenible es aquello que tiene recibo en la conciencia y en el corazón de la ciudadanía (semana.com, 2009, junio 5)». José Obdulio Gaviria, su ideólogo preferido, ha calificado a Álvaro Uribe como «una inteligencia superior» (semana.com, 2007, octubre 17).

Comparemos las palabras de Benito Mussolini sobre el fascismo, la democracia y el Estado, de su ensayo El fascismo y las de Álvaro Uribe y José Obdulio Gaviria:

El fascismo, (...) tiene una forma que corresponde a las contingencias de lugar y tiempo, e igualmente encierra una contenido ideológico que lo eleva al rango de verdad axiomática en la historia superior del pensamiento humano $(1935,9)$.

El fascismo, por lo tanto se opone a la democracia que asimila el pueblo a la mayoría de individuos y lo rebaja a ese nivel. Y sin embargo, es la forma más pura de la democracia. Por lo menos, si el pueblo es concebido, como debe serlo, en su aspecto cualitativo y no cuantitativo, si significa la idea más 
poderosa, por ser la más moral, la más coherente, la más verdadera que se encarna en el pueblo como conciencia y voluntad de un pequeño número o de uno solo como un ideal que tiende a realizarse en la conciencia y en la voluntad de todos (p. 17 y 18).

Al referirse al Estado y a su contenido, Mussolini manifestó:

El Estado fascista, la forma más elevada y más poderosa de la personalidad, es una fuerza, pero una fuerza espiritual. Una fuerza que resume todas a las formas de la vida moral e intelectual del hombre. No se puede, pues, limitarlo a puras funciones de orden y de protección como pretendía el liberalismo. No es un simple mecanismo que limita la esfera de las llamadas libertades individuales. Es una forma, una regla interior y una disciplina de toda la persona; penetra en la voluntad y la inteligencia (p. 9).

Es conocido el ultra chovinismo de «Gran Nación» y la teoría del «espacio vital» de Adolfo Hitler y su doctrina Nazi, expansionista e imperialista, que desató la II Guerra Mundial. También, su irracionalismo racista, que consideraba los arios como un pueblo con una gran historia y cultura, una raza pura y superior. Los judíos, su «antítesis», un pueblo sin historia, sin cultura, ignorante e inferior, todo lo cual lo llevó a los guetos, los campos de concentración, las cámaras de gas, el genocidio de millones de judíos en la llamada «solución final», en aplicación de los sofismas ideológicos y políticos de su doctrina Nazi (Hitler, 2014; Chevallier, 1995, 335-358).

Con estos sofismas ideológicos del «Estado de opinión, como etapa superior del Estado de Derecho», de Álvaro Uribe, dotado de una «inteligencia superior», que lo hace un ser superior, y la democracia «como conciencia y voluntad de un pequeño número o de uno solo» de Benito Mussolini, se llega a la práctica del caudillo, que establece la relación directa con la «opinión», convirtiéndose en el único intérprete y en su nombre, se proclama la autoridad suprema, con el ejercicio de todos los poderes, sin intermediaciones, instituciones y sin límites de ninguna naturaleza. Lo anterior, acompañado de la «raza superior», de la ideología extremo derechista y anticomunista, expresada en la denominación uribista del "castrochavismo», de la entrega de Colombia a los terroristas de las FARC. Se abre el camino para el tránsito hacia un régimen autoritario, caracterizado como neofascista y disfrazad de «estado de opinión».

José Obdulio Gaviria en nombre de Álvaro Uribe, hizo las siguientes declaraciones a Darío Arizmendi:

... una vez en Madrid, donde estaba viviendo por amenazas de las Farc, me reuní con cierta reticencia con José Obdulio Gaviria. Palabras más, palabras 
menos, me dijo que me traía un mensaje del presidente Uribe: que él se iba a lanzar para la reelección y que me pedía que lo apoyara. Le dije que no, y que me parecía un antecedente gravísimo porque después iba a querer la tercera, tal y como lo intentó. Después le pregunté a José Obdulio Gaviria: ¿qué es lo que ustedes quieren hacer en el poder? Y me respondió: queremos gobernar 20 o 30 años, como lo hizo La Falange en España con Franco. Que si un presidente es bueno debe ser reelegido las veces que sean necesarias, y me anunció que el próximo presidente, después de Uribe, iba a ser Uribito. Rechacé la propuesta, porque soy un liberal de ideas y porque Caracol es una organización que respeta la democracia (Arizmendi, 2019, septiembre 9).

Es evidente la simpatía del uribismo por la Falange, versión española del fascismo ${ }^{13}$ y por la dictadura criminal y fascista del General Francisco Franco, golpista y usurpador del poder político, quien después de desatar una Guerra civil (1936-1939) ahogó en sangre y fuego la Segunda República española y restauró la monarquía de los borbones, con la intervención directa de la Italia fascista de Mussolini y la Alemania Nazi de Hitler.

De acuerdo con el politólogo español, Ramón Cotarelo,

El régimen salido de la guerra se basó en el terror, la represión generalizada, los asesinatos, las torturas, el miedo a la arbitrariedad. Las más radical inseguridad jurídica de un país ocupado por su propio ejército y con una población civil a merced de los vencedores, gran parte de la cual, sectores populares y clases medias y profesionales, hubo de soportar todo tipo de sevicias, confiscaciones, represalias e intimidaciones en una situación de abandono y desprotección ante los desmanes de las cuadrillas de pistoleros falangistas y a la Guardia Civil (2011, p. 39). Negrilla fuera del texto original.

Luigi Ferrajoli, jurista y filósofo del derecho italiano, advierte: «En efecto, no podemos olvidar que las amenazas más graves para la democracia provienen hoy de dos potentes ideologías de legitimación del poder: la idea de la omnipotencia de las mayorías políticas y la idea de la libertad de mercado como nueva Grund-norm ${ }^{14}$ del presente orden globalizado» (2006, p. 84).

El régimen uribista, vigente por tercera vez, desde el 7 de agosto de 2018, reúne los dos componentes, que amenazan la precaria democracia colombiana: a. El autoritarismo político, establecido desde la presidencia de la República con Iván Duque (2018-2022), (en el actual régimen constitucional presiden-

13 Ver: Falange. Historia del fascismo español (Payne, 1985).

14 Norma básica. 
cialista), y con la presidencia del nuevo Congreso en el primer periodo legislativo (20 de julio 2018-20 de julio 2019) con Luis Ernesto Macías. También, sus avances en la administración de justicia, como el nombramiento de su cercano ideológico Néstor Humberto Martínez como fiscal general. Se agrega la curiosa y silenciosa penetración en las altas cortes, como el caso de Cristina Lombana, elegida «como magistrada de la Sala de Instrucción de la Corte Suprema de Justicia, siendo al mismo tiempo mayor del Ejército Nacional, es uno de los episodios más polémicos que enfrenta el alto tribunal recientemente (Semana.com, 2019, junio 20».

La ola de terror continúa y se agrava, con el asesinato sistemático, por parte de los narcoparamilitares y usurpadores de tierras, de los defensores de los derechos humanos, de líderes sociales, reclamantes de tierras y desmovilizados de las FARC, organizados en un partido político reconocido legalmente (Matias Camargo, 2018, enero-junio). Entre el 1 de enero de 2016 y el 28 de febrero de 2019, «fueron asesinados 462 líderes sociales y defensores de derechos humanos, según datos de la Defensoría del Pueblo (ADN, 2019, junio 12, p. 6)». Entre el 1 de enero y el 3 de abril de 2019, la ONU Derechos Humanos «...recibió un total de 51 quejas sobre asesinatos de defensores de derechos humanos en el país. De estos, se ha logrado la verificación de 21 casos, entre los que se reportan los homicidios de tres mujeres y 18 hombres (Publimetro, 2019, junio 4, p. 2)».

El Instituto de Estudios para el Desarrollo y la Paz (Indepaz) y su presidente, Camilo González Posso, informan:

Desde cuando se firmó el Acuerdo de Paz, en noviembre de 2016, a junio de 2019 se han presentado 135 homicidios de excombatientes y 35 de familiares de ex integrantes de la guerrilla. En la mayoría de los casos los victimarios no han sido identificados, pero la hipótesis más probable es que buena parte de esos homicidios han sido ordenados por negociantes y políticos de las zonas en donde estuvieron las Farc y quienes, ahora, se oponen a que el partido FARC ejerza algún liderazgo. También hay casos de venganza por deudas de guerra. Un número tan elevado de homicidios de integrantes del nuevo partido indica que están fallando las garantías que debe ofrecer el Estado (Orozco, 2019, p. 16).

Se destaca, por su gravedad, el homicidio del desmovilizado integrante de las FARC, Dimar Torres, el 23 de abril de 2019, en el puesto de control permanente del Batallón de Operaciones Terrestres n. ${ }^{\circ} 11$, en el municipio de Convención (Norte de Santander), constitutivo de una ejecución extrajuducial, un delito de lesa humanidad, cometido por militares activos, en ejercicio de sus funciones, comandados por el cabo Daniel Eduardo Gómez Robledo. Roy Barreras, 
Iván Cepeda, Antonio Sanguino y Juan Carlos Losada, como delegados de la Comisión de Paz del Senado, en visita oportuna realizada, pudieron verificar presencialmente la verdad de los hechos criminales y las circunstancias de tiempo, modo y lugar de su ocurrencia. Barreras expresó: «Aunque será la Fiscalía la que determine los detalles del suceso, es evidente que la muerte de Dimar Torres no fue un hecho accidental, se trata de un homicidio en persona protegida...Para la Comisión de Paz, no es solo un asesinato, es además un riesgo para el Proceso de Paz porque el Acuerdo firmado implica primero respetar la vida de quienes dejaron las armas (elespectador.com, 2019, abril 28)».

Después de torturar y asesinar a Torres, los autores del crimen intentaron enterrar su cuerpo para desaparecerlo, lo cual se pudo evitar por la oportuna presencia de las comunidades campesinas, delegados de la Comisión de Paz del Congreso de la República y de las Naciones Unidas, que pusieron en evidencia la verdad de estas conductas criminales, conscientemente cometidas. El ministro de Defensa Guillermo Botero, intentó justificar estos hechos criminales diciendo que había sido por un forcejeo con los militares; pero, ante la veracidad de las evidencias denunciadas oportunamente, manifestó que si había ocurrido un homicidio, había sido por algún motivo (elespectador.com, 2019, abril 28).

Houria Es-Slami, Luciano Hazan, Henrikas Mickevi?ius, Bernard Duhaime, Agnès Callamard y Tae-Ung Baik, relatores especiales del Consejo de Derechos Humanos de la ONU, con ocasión del asesinato de Dimar Torres, se pronunciaron por medio de un comunicado, enviado al Gobierno nacional el 4 de julio: «Instamos al gobierno colombiano a que deje de incitar a la violencia contra los desmovilizados de las FARC-EP y a cumplir con las garantías que se les otorgaron durante las negociaciones en La Habana, sobre todo el respeto al derecho a la vida. El aparente desprecio de estas garantías a nivel estatal es perjudicial para la paz, el desarrollo y la estabilidad. El Gobierno debe tomar medidas inmediatas para implementar los acuerdos de paz (elespectador.com, 2019, junio 6)».

El alto consejero para la Estabilización y la Consolidación, Emilio Archila, en representación del Gobierno Nacional, respondió a los relatores especiales del Consejo de Derechos Humanos de la ONU: «Es totalmente inaceptable la afirmación de que existe un "aparente desprecio de estas garantías a nivel estatal", así como la sugerencia de que el Gobierno no está tomando medidas para implementar los acuerdos... Es absolutamente infundado que una actuación u omisión del Estado haya incentivado actos violentos en contra de excombatientes de las antiguas FARC. El Gobierno no ha incitado a la violencia contra ningún desmovilizado de las FARC» (elespectador.com, 2019, junio 5). Archila calificó la reclamación de los 
relatores especiales del ONU como «infundada» e «irresponsable» (CNN Español, 2019, junio 5).

Los hechos anteriores, junto a las instrucciones eficientistas, con reportes de los cadáveres de sus muertos (denunciadas por el New York Times), elaboradas por el comandante del Ejército Nacional Nicacio Martínez, quien fue ascendido a general de cuatro soles, no obstante las denuncias de José Miguel Vivanco y Human Rights Watch (Molano, 2019, junio 5), que han despertado las alertas sobre la repetición de las ejecuciones extrajudiciales, sistemáticas de civiles, presentadas como bajas en combate, constitutivos de delitos de lesa humanidad, denominados «falsos positivos» que comprometen a más de dos mil militares y al comandante del Ejército Nacional, general Mario Mora Rangel, ocurridas en los ochos años del gobierno de Álvaro Uribe (2002-2010), quien ejerce un tercer periodo, en cuerpo ajeno, con Iván Duque (2018-2022) (Casey, 2019, mayo 18).

Según el artículo de Nicholas Casey, Las órdenes de letalidad del ejército colombiano ponen en riesgo a los civiles, según oficiales, publicado por el New York Times, se incluyeron instrucciones, que podían revivir los «falsos positivos», ocurridos en la década de 2000.

El comandante del ejército de Colombia, frustrado por los vacilantes esfuerzos de la nación para preservar la paz, les ha ordenado a sus tropas que dupliquen la cantidad de criminales y rebeldes que matan, capturan u obligan a rendirse en batalla; y posiblemente acepte un aumento de las bajas civiles en el proceso, según consta en órdenes escritas y entrevistas con altos oficiales.

A inicios de año, los generales y coroneles colombianos se reunieron y se les pidió que firmaran un compromiso por escrito para intensificar los ataques. Las presentaciones internas diarias ahora muestran el número de días que las brigadas han pasado sin estar en combate, y los comandantes son amonestados cuando no realizan operaciones con la frecuencia suficiente, dijeron los oficiales.

Una orden que causa especial preocupación instruye a los soldados que no «exijan perfección» al momento de ejecutar ataques letales, incluso si tienen preguntas significativas sobre los objetivos que están atacando. Algunos militares dicen que esa orden implica que reduzcan sus normas para proteger a civiles inocentes de ser asesinados, y que ya ha ocasionado muertes sospechosas o innecesarias (2019, mayo 18).

Se hace referencia a las ejecuciones extrajudiciales, ocurridas a mediados de la década de 2000, antes de la firma del acuerdo de paz histórico, que finalizó décadas de conflicto. 
Los militares implementaron una estrategia similar para derrotar a los grupos rebeldes y paramilitares de Colombia a mediados de la década de los 2000, antes de que se firmara un acuerdo de paz histórico que finalizó con décadas de conflicto.

Pero esas tácticas causaron la indignación nacional cuando se supo que los soldados, con el objetivo de cumplir sus cuotas, cometieron asesinatos generalizados y desaparición de civiles (Romero, The New York Times, 2008, octubre 29).

Ahora, otra encarnación de esa política está siendo impulsada por el nuevo gobierno contra los grupos criminales, guerrilleros y paramilitares del país, según las órdenes revisadas por The New York Times y tres oficiales de alto rango que hablaron sobre esas medidas.

Las nuevas órdenes han generado incomodidad entre los militares. El ejército de Colombia sigue siendo investigado por la serie de asesinatos ilegales ocurridos a mediados de la década de 2000, conocidos como «falsos positivos».

Los soldados mataban a campesinos y afirmaban que eran guerrilleros, a veces incluso vistiéndolos con uniforme y plantando armas cerca de sus cuerpos. Las tácticas surgieron de los superiores que exigían un mayor número de cuerpos, de acuerdo con los fiscales (Casey, 2019, mayo 18).

Se continúa con las informaciones dadas por los militares informantes.

En largas entrevistas, dos oficiales dijeron que los soldados colombianos vuelven a estar bajo una intensa presión y que este año ha comenzado a surgir un patrón de asesinatos sospechosos y encubrimientos.

En una reunión relatada por uno de los oficiales, un general ordenó a los comandantes "hacer lo que sea" para mejorar sus resultados, incluso si eso significaba «aliarse» con grupos criminales armados para obtener información sobre objetivos, una estrategia de dividir y conquistar.

Más allá de eso, dijeron los oficiales, a los soldados que aumentan sus muertes en combate se les ofrecen incentivos como vacaciones extra, un patrón que temen es notablemente similar al de los asesinatos ilegales ocurridos a mediados de la década de los 2000 (2019, mayo 18).

El presidente del Instituto de Estudios para el Desarrollo y la Paz (Indepaz), Camilo González Posso, confirma la reaparición de grupos narcoparamilitares 
con dominio local y, de nuevo, la existencia de alianzas entre ellos y el poder político y económico tradicional.

Al referirse a la relación entre el poder político antiacuerdo de paz y el crecimiento de la violencia, González Posso afirma:

Hay una correlación entre el desconocimiento y la oposición al Acuerdo de Paz, y la persistencia de violencias armadas y agresión a comunidades y líderes. Por ejemplo, dejar entre la espada y la pared a más de $400 \mathrm{mil} \mathrm{fami-}$ lias de las zonas de influencia cocalera que quieren entrar en los pactos de sustitución; descalificar radicalmente el Acuerdo de Paz que se negoció en La Habana, y afirmar que la Jurisdicción Especial para la Paz (JEP), es impunidad y que los excombatientes solo merecen cárcel y ser llamados criminales, violadores y cosas parecidas propicia un ambiente para que se mantengan, en muchos sectores y territorios, conductas violentas y justicia privada. El énfasis en la estigmatización del Acuerdo viene más del partido de gobierno que del mismo Gobierno. Pero este es empujado por los fanáticos de ultraderecha a frenar o a congelar la implementación del Acuerdo y a recurrir a mayor estigmatización (Orozco, 2019, p. 17).

Al comentar la responsabilidad política del Gobierno, del Centro Democrático y de los sectores de ultraderecha en el recrudecimiento de la violencia social en las regiones, el director de Indepaz reitera que «...la falta de implementación de los Acuerdos facilita la acción de mafias y grupos ilegales, y la recomposición de grupos violentos. Además, los discursos de odio que se proclaman desde las esferas más altas del partido de gobierno tienen repercusión en la base de la sociedad y refuerzan la persistencia de la cultura de la violencia y de la guerra (Orozco, 2019, p. 17)».

b. El neoliberalismo económico/social, constitutivo de la dictadura del mercado, con el Estado a su servicio y el de los grandes terratenientes y capitalistas criollos y transnacionales, que a su vez necesitan del autoritarismo y de sus ataques a la democracia, para su implementación, en este cuatrienio presidencial, se sigue implementando y profundizando (Ahumada, 1996; Lander, 2012; Matias Camargo, 2013).

El Gobierno de Duque continúa con el proceso de búsqueda de otro operador privado para Electricaribe, iniciado en el gobierno anterior, después de que la multinacional española Gas Natural Fenosa la saqueó y la convirtió en la peor empresa de servicios públicos domiciliarios de Colombia. El ministro de Hacienda, Alberto Carrasquilla, anuncia poner en venta activos del Estado, por un valor de entre 10 y 15 billones de pesos, «...lo que equivaldría a dos reformas tributarias como la que acaba de pasar, y supondría, asimismo, una gran 
pérdida del patrimonio del Estado, solo para cubrir el déficit fiscal que para 2014 se proyectó en 2,4 \% del PIB (CMI, 2019, junio 19)». La privatización de las empresas públicas se inicia con Interconexión Eléctrica SA (ISA), «...aprovechando el muy buen momento de la empresa que le permitió aumentar en casi $90 \%$ el valor de su acción en los últimos 4 años: de $\$ 8.190$ a $\$ 15.500$. ISA ya está estructurando su modelo para desarrollar en Colombia y Perú el negocio de concesiones viales y avanzar en los de transporte de energía y telecomunicaciones (dinero.com, 2019, mayo 17)». Se ha previsto la venta de activos públicos por valor de 30 billones de pesos, contando entre ellos el $8.5 \%$ de las acciones de Ecopetrol. En el Marco Fiscal de Mediano Plazo (MFMP), se considera la venta de activos públicos por 5 billones de pesos (Semana, 2019, mayo 19, p. 64).

En Colombia, desde sus orígenes republicanos bicentenarios, se introdujo constitucionalmente la teoría de la división orgánica y funcional del Poder Político, que hunde sus raíces históricas en las instituciones políticas de la antigua democracia griega (Aristóteles, 2000) y la república romana y en la modernidad, desarrolladas institucional y filosóficamente en la Inglaterra del siglo XVII y en la Francia del siglo XVIII, contando con pensadores como John Locke (Ensayo sobre el gobierno civil, 1981) y Charles Louis Montesquieu (El espíritu de las leyes, 1993). Son avances democráticos y republicanos de la sociedad humana, para superar las autocracias, las monarquías y el absolutismo, la concentración total del poder humano y divino, actualmente remplazados por el autoritarismo, el totalitarismo, las dictaduras civiles y militares y el neofascismo (Kelsen, 1934; Villar, 2007) ${ }^{15}$.

Los hechos referidos y la teoría del «estado de opinión, como forma superior del estado de derecho» y de Uribe como «inteligencia superior» anteriormente analizadas, caracterizan el régimen político social vigente en Colombia, que atacan los avances democráticos y republicanos, para reversarlos (Borón, 2019). Son una alerta temprana, evidencias empíricas, que hacen recordar el ascenso al poder de Mussolini y Hitler, los fascistas y los nazis, quienes lo conquistaron bajo las banderas de sus programas racis-

15 «La oposición esencial se plantea entre autocracia y democracia. La autocracia puede estar constituida por una monarquía o, en la política contemporánea, por una dictadura. No existen en la realidad Estados absolutamente democráticos, como lo observa William Ebenstein, pues frecuentemente ocurre que junto a una legislatura democrática haya un ejecutivo y un judicial autocrático. Que sea lo uno o lo otro, democrático o autocrático, deberá determinarse por el predominio de los elementos esenciales a cada uno de estos sistemas» (Villar, 2006, 137-138). Estas tesis ameritan un análisis del Espíritu de las Leyes de Montesquieu (Montesquieu, 1993) y del Contrato social de Rousseau (Rousseau, 1985). 
tas irracionales y chovinistas extremos, inicialmente por las vías electorales, por la democracia política, que la utilizaron para asesinarla. Posteriormente, establecieron en Italia y Alemania «la dictadura terrorista descarada de los elementos más reaccionarios, más chovinistas y más imperialistas del capital financiero (Dimitrov, 1960, p. 90)» ${ }^{16}$. Con las banderas de la «gran nación», del «espacio vital necesario» y de la «raza pura y superior», desataron una política expansionista, imperialista. Su objetivo, dominar Europa y el mundo, con sus campos de concentración y genocidios, que generaron la Segunda Guerra Mundial (1939-1945), dejando más de sesenta millones de muertos, hambre, miseria, destrucción, en nombre de sus ideologías criminales, sus programas y sus sofismas ideológicos y políticos. ${ }^{17}$

El actual contexto internacional es del imperialismo tardío, que «...se refiere al actual periodo del monopolio: capital financiero y estancamiento, disminución de la hegemonía de Estados Unidos y aumento del conflicto mundial, acompañado de crecientes amenazas a las bases ecológicas de la civilización y la vida misma. Es el núcleo de las relaciones extremas y jerárquicas que rigen la economía mundial capitalista en el siglo XXI, cada vez más dominada por las corporaciones mega-multinacionales y un puñado de estados en el centro del sistema mundial (Foster, 2019)».

Asistimos a un Nuevo Orden Mundial en condiciones de deterioro, de Estados Unidos, calificado de "superpotencia solitaria" por Samuel Huntington

16 En América Latina, basta citar el ejemplo representativo del ascenso al poder de la dictadura militar fascista/neoliberal y pro estadounidense de Augusto Pinochet el 11 de septiembre de 1973, que confirma las anteriores afirmaciones (Matias Camargo, 2013, pp. 69-86). "Particularidades del régimen fascista. En defensa de sus intereses amenazados por la política del gobierno de Salvador Allende, el imperialismo y la reacción local chilena realizaron el golpe de Estado que puso fin a la experiencia de la Unidad Popular e imponen la dictadura cívico-militar fascista (...) La llegada al poder del capital financiero cambió las características del Estado, lo que ratifica nuevamente la tesis de Dimitrov: «la subida del fascismo al poder no es un simple cambio de un gobierno burgués por otro, sino la sustitución de una forma estatal de la dominación de clase de la burguesía -la democracia burguesa- por otra, por la dictadura terrorista abierta» (Yanes Guzmán, 1984).

17 Dominika Bernáthová, analista checa y Filóloga Hispánica por la Universidad Carolina de Praga, con ocasión de los setenta y cuatro años del Día de la Victoria (derrota de los ejércitos nazi-fascistas) celebrados el 8 de mayo de 2019 en la República Checa y en Europa, concluyó: «Durante 2194 días, la Segunda Guerra Mundial se cobró más de 60 millones de vidas, de ellas más de 320.000 checoslovacos. El conflicto involucró a 70 países y los enfrentamientos bélicos se desarrollaron en el territorio de 40 estados. La contienda se acabó oficialmente en el Viejo Continente el 8 de mayo de 1945, no obstante, en Bohemia Central se prolongaron los enfrentamientos con las tropas alemanas hasta el 11 de mayo» (2019). 
(Huntington, 1999, pp. 9-24), cada día más agresivo, con guerras y bloqueos comerciales, chantajes militares, tendientes a recuperar sus espacios perdidos. La confrontación entre una globalización hegemónica y otra contrahegemónica (Santos, 2009) de choque entre las fuerzas decadentes y las renacientes y en crecimiento, como Rusia, China, India, los Brics. Paralelamente, las tendencias neofascistas han resurgido y «Cada vez más, el neoliberalismo se está fusionando con el neofascismo, desatando el racismo y el nacionalismo revanchista (Foster, 2019)».

\section{CONCLUSIONES}

La Justicia Especial para la Paz (JEP), es una parte importante del Sistema Integral de Verdad, Justicia, Reparación y No Repetición (SIVJRNR), incluido en el Punto 5 del Acuerdo de Paz y en la Constitución Política de Colombia. Su implementación y puesta en funcionamiento pleno, es un requisito fundamental del cumplimiento de los Acuerdos de paz con las Farc, para la ejecución de la justicia transicional, una garantía para las víctimas del conflicto armado y la consolidación de su solución política.

Ponerle trabas, desnaturalizarla o eliminarla, es una conducta regresiva, que pretende revivir todos los medios, incluidos los de la guerra sucia, como los «falsos positivos», ejecuciones extrajudiciales, verdaderos delitos de lesa humanidad, que de acuerdo con las denuncias del New York Times, el eficientismo militarista, medido en muertos, constituye un alto riesgo de volver a esa práctica criminal, según la cual el fin justifica los medios.

La objeciones del presidente Iván Duque contra la JEP, su Ley estatutaria, el fallo de exequibilidad de la Corte Constitucional, y su desconocimiento como cosa juzgada constitucional, hacen parte de la estrategia guerrerista de la extrema derecha, encabezada por el partido Centro Democrático, su fundador y caudillo Álvaro Uribe, a la cual se ha sumado Néstor Humberto Martínez, en su condición de fiscal general, quien desde su comienzo se opuso a los Acuerdos de Paz y su implementación. El propósito inmediato, eliminar la JEP, los Acuerdos de Paz con las Farc, crear un estado de terror, que se ya se ha desatado con los asesinatos de cientos de líderes sociales, reclamantes de tierras, defensores de derechos humanos, desmovilizados farianos. Volver a las soluciones de fuerza, a la guerra sucia, a las ejecuciones extrajudiciales,

La acción del Centro Democrático en el Congreso, sus proyectos de reforma constitucional y de leyes, la promoción de referendos contra la JEP, las Cortes y el Congreso, acompañado de una campaña de desprestigio contra la administración de justicia a la que se acusa de persecución política, busca reducirlos 
a su mínima expresión y concentrar poder en un Presidente cuasimonárquico. La alternativa ante la "catástrofe" generalizada, es el caudillo con "inteligencia superior", elevado a la categoría de mesías salvador por el "estado de opinión", quien por destino manifiesto debe gobernar hegemónicamente, en forma indefinida por el ser el único capaz de liberar a Colombia del castrochavismo y de la entrega a los terroristas. A lo anterior, se suman las confesiones de José Obdulio Gaviria a Darío Arizmendi, en nombre de Álvaro Uribe, según las cuales, este aspiraba a su reelección y a querer "gobernar 20 o 30 años, como lo hizo La Falange ${ }^{18}$ en España con Franco (Arizmendi, Semana, septiembre 9)». Se recuerda, que Uribe se reeligió, haciendo reformar a su favor un "articulito" de la Constitución Política, que la prohibía y su tentativa de segunda reelección fue evitada por la Corte Constitucional.

Los hallazgos revelados, son alertas tempranas, que dejan en evidencia, la estrategia uribista de derrocar el Estado Constitucional de Derecho y reemplazarlo por una dictadura neofascista, disfrazada de "Estado de opinión" al servicio de las fuerzas retardatarias, del poder terrateniente, de las oligarquías financieras y de los monopolios transnacionales, en contravía de los intereses nacionales y populares y de la democracia constitucional. En un contexto internacional de imperialismo tardío, de disminución de la hegemonía de Estados Unidos, cada día más agresivo, intentando recuperar sus espacios perdidos. Asistimos a un Nuevo Orden Mundial en condiciones de deterioro, de choque entre las fuerzas decadentes y las renacientes y en crecimiento, en el cual las tendencias neofascistas han resurgido y cada vez más, el neoliberalismo se está fusionando con el neofascismo.

La existencia y garantía del funcionamiento de la JEP, del Sistema Integral de Verdad, Justicia, Reparación y No Repetición, la implementación justa, democrática y necesaria de los Acuerdos de Paz con las Farc, el freno de las actuales amenazas a la democracia y su existencia dependen de la solidaridad y el respaldo masivos de las fuerzas progresistas, que reversen el avance de las fuerzas retardatarias, el autoritarismo y las corrientes neofascistas.

La paz es un derecho fundamental y un deber de obligatorio cumplimiento, proclama la Constitución Política de Colombia (art. 22 C. P.), puesta en alto riesgo por el actual Gobierno Nacional, las bancadas oficialistas del Congreso de la República, las fuerzas políticas, gremiales y sociales retardatarias. Es necesaria la movilización social en defensa de la JEP, del Sistema Integral de Verdad, Justicia, Reparación y No Repetición, de los Acuerdos de Paz, de su pronta y justa implementación, de la democracia y del Estado Constitucional de derecho.

18 Ver: Falange. Historia del fascismo español (Payne, 1985). 


\section{REFERENCIAS}

ADN. (2019, junio 12). Líderes sociales son prioridad para la UE. Bogotá. EFE, p.6.

ADN. (2019, marzo 21). Corte espera al Congreso. Redacción Bogotá. p.8.

ADN. (2019, marzo 19). Miles de personas se manifestaron por paz. Bogotá. EFE, p. 2.

Ahumada, C. (1996). El modelo neoliberal y su impacto en la sociedad colombiana. El Áncora Editores, Bogotá, Colombia.

Aristóteles. (2000). La Política. Bogotá: Panamericana Editorial.

Arizmendi, D. (Semana, septiembre 9). "No me quedaré mordiéndome la lengua": Darío Arizmendi. Recuperado de https://cuartodehora.com/2019/07/08/queremos-gobernar-20-o-30-anos-jose-obdulio-gaviria/

Arboleda Zárate, L. \& Molano Jimeno, A. (2019). Detalles del desayuno entre Whitaker y congresistas. El «lobby» del embajador Kevin Whitaker por las objeciones. Recuperado de https://www.elespectador.com/noticias/politica/detalles-del-desayuno-entre-whitaker-y-congresistas-articulo-850317

Asamblea Nacional Constituyente de Colombia. 1991. (2014). Constitución Política de Colombia. Bogotá: Corte Constitucional, Sala Administrativa y CENDOJ.

Barreras, R. (2019, junio 18). Constancia realizada en Comisión Primera del Senado. Postura sobre el «Estado de Opinión». Junio 18 de 2019. Recuperado de https:/ / www.facebook.com/roybarrerassenador/videos/vb.675375532494252/44588865 $9304157 /$ ?type $=2 \&$ theater

BBC. (2019, marzo 21) JEP: la Corte Constitucional de Colombia rechaza pronunciarse sobre las polémicas objeciones de Duque a la justicia para la paz. ¿Qué pasará ahora? BBC News Mundo en Colombia. Recuperado de https:/ / www.bbc.com/ mundo/noticias-america-latina-47647953

Bernáthová, D. (2019, mayo 8). Los estadounidenses no llegaron hasta Praga. Radio Praga. Recuperado de https:/ / radio.cz/es/rubrica/especiales/los-estadounidenses-no-llegaron-hasta-praga

Borón, A. (2019). Atilio Borón y la actitud de la izquierda. Recuperado de http:/ / www.elsiglo.cl/2019/01/19/atilio-boron-y-la-actitud-de-la-izquierda/

Cámara de Representantes de Colombia (2019). Informe de rechazo de las objeciones presidenciales al proyecto de ley estatutaria 008/17 Senado- 016/17 Cámara «Estatutaria de la Administración de Justicia en la Jurisdicción Especial para la 
Paz» e insistencia en el texto aprobado por la Corte Constitucional. Recuperado de http:/ / static.iris.net.co/semana/upload/documents/71c64b_a4e7dc1d4d1847 23a35e86b05b9ef030.pdf

Casey, N. (2019, mayo 18). Las órdenes de letalidad del ejército colombiano ponen en riesgo a los civiles, según oficiales. Recuperado del The New York Times, de https:/ /www.nytimes.com/es/2019/05/18/colombia-ejercito-falsos-positivos/

Caracol Radio (2019, junio 6). Uribe buscará eliminar la JEP a través de una reforma. La propuesta la lanzó a la bancada del Centro Democrático. Recuperado de 2019 de https:/ / caracol.com.co/radio/2019/06/07/politica/1559869629_216068.html

Chevallier, J. J. (1997). Las grandes obras políticas. Desde Maquiavelo hasta nuestros días. Bogotá: Editorial Temis S. A.

CMI. (2019, junio 19). Lista de empresas del sector energético, parte de cuyas acciones vendería el Gobierno. Recuperado de Noticias/uno-dos-tres de https:// canal1.com.co/noticias/uno-dos-tres/uno-lista-de-empresas-del-sectorenergetico-parte-de-cuyas-acciones-venderia-el-gobierno/

CNN Español (2019, junio 5). ONU le pide al Gobierno de Colombia que no «incite» a la violencia contra excombatientes de las FARC. Recuperado de https:// cnnespanol.cnn.com/2019/06/05/onu-le-pide-al-gobierno-de-colombia-que-noincite-a-la-violencia-contra-excombatientes-de-las-farc/

Congreso de la República de Colombia (1991). Constitución Política de Colombia. Recuperado de http:/ / www.secretariasenado.gov.co/index.php/constitucionpolitica

Congreso de la República de Colombia. (2019). Ley Estatutaria de la Administración de Justicia en la Jurisdicción Especial para la Paz. Recuperado de http:/ / comision primerasenado.com/index.php?option=com_joodb\&task=getFileFrom Blob\& joobase $=7 \&$ id $=171 \&$ field=ver_ley

Congreso de la República de Colombia. (2017). Proyecto de ley Estatutaria de la Administración de Justicia en la Jurisdicción Especial para la Paz. Recuperado de http: / / comisionprimerasenado.com/proyectos-de-ley-en-tramite/171-proyecto-de-leyestatutaria-no-08-de-2017-senado-016-de-2017-camara-estatutaria-de-laadministracion-de-justicia-en-la-jurisdiccion-especial-para-la-paz-procedimientolegislativo-especial-p

Congreso de la República de Colombia. (1992). Ley nro. 5 de 1992. (junio 17). Por la cual se expide el Reglamento del Congreso; el Senado y la Cámara de Representantes. Diario Oficial nro. 40.483 de 18 de junio de 1992. Recuperado de http:/ / www.secretariasenado.gov.co/index.php/ley-5-de-1992 
Corte Constitucional de Colombia. (2018a). Control de constitucionalidad del Proyecto de Ley Estatutaria Número 08 de 2017 Senado-016 de 2017 Cámara, «Estatutaria de la Administración de Justicia en la Jurisdicción Especial para la Paz». Sentencia C-080/18. M. P. Antonio José Lizarazo Ocampo. Comunicado nro. 32. Agosto 15 de 2018. Recuperado de http://www.corteconstitucional.gov.co/relatoria/ 2018/c-080-18.htm

Corte Constitucional de Colombia. (2018b). Control automático de constitucionalidad del Proyecto de Ley Estatutaria número 08 de 2017 Senado, 016 de 2017 Cámara, «Estatutaria de la Administración de Justicia en la Jurisdicción Especial para la Paz». Sentencia C-080/18. M. P. Antonio José Lizarazo Ocampo. Recuperado de file:/ / /F:/CORTE $\% 20$ CONSTITUCIONAL $\% 20$ No. $\% 2032 \% 20$ comunicado \%2015\%20de\% 20agosto\%20de\%202018\%20ley\%20estatutaria\%20JEP.pdf

Corte Constitucional de Colombia. (1998). Efecto erga omnes de las decisiones. Sentencia C-600/98. M.P. José Gregorio Hernández Galindo. Recuperado de http:/ / www.corteconstitucional.gov.co/relatoria/1998/c-600-98.htm

Cotarelo R. (2011). Memorias del franquismo. Madrid: Ediciones Akal, S. A.

Dimitrov, J. (1960). El fascismo y la clase obrera. Obras Escogidas. Sofía: Editorial en lenguas extranjeras.

dinero.com. (2019, mayo 17). En marcha la venta de ISA. Recuperado el 10 de mayo de 2019 de https://www.dinero.com/empresas/confidencias-on-line/articulo/ arranca-la-venta-de-isa/272180

Donato, O \& González Monguí, P. E. (2011). Bogotá: Universidad Libre.

Duque Márquez, I. (2019). La paz que nos une. Alocución del presidente Iván Duque Márquez sobre la Ley Estatutaria de la Justicia Especial Para La Paz (JEP). Recuperado de https://id.presidencia.gov.co/Paginas/prensa/2019/190310-Alocuciondel-Presidente-Ivan-Duque-Marquez-sobre-la-Ley-Estatutaria-de-la-JusticiaEspecial-Para-La-Paz-JEP.aspx

elespectador.com. (2019, junio 5). «No incentivamos violencia contra excombatientes»: Gobierno a relatores de la ONU. Recuperado de https:/ / www.elespectador.com/ noticias/politica/no-incentivamos-actos-violentos-contra-excombatientes-gobierno-relatores-de-derechos-humanos-de-la-articulo-864347

elespectador.com. (2019, mayo 29). El final de las objeciones presidenciales a la JEP. elespectador.com. Recuperado de https://www.elespectador.com/noticias/judicial/las-objeciones-la-jep-si-se-hundieron-en-el-congreso-corte-constitucional-articulo-863299 
elespectador.com. (2019, mayo 1). «Las objeciones fueron rechazadas ayer»: Guillermo Rivera, exministro del Interior. elespectador.com. Política. Recuperado de https:/ / www.elespectador.com/noticias/politica/las-objeciones-fueron-rechazadas-ayerguillermo-rivera-exministro-del-interior-articulo-853213

elespectador.com. (2019, abril 28). Homicidio de Dimar Torres fue una ejecución extrajudicial: Comisión de Paz. Recuperado de Redacción Judicial de https:// www.elespectador.com/noticias/judicial/homicidio-de-dimar-torres-fue-unaejecucion-extrajudicial-comision-de-paz-articulo-852708

elespectador.com. Redacción Política. (2019, febrero 7). Cámara señala a Macías de omitir apartes de la JEP antes de enviarla a sanción presidencial. Recuperado de https://www.elespectador.com/noticias/politica/camara-senala-macias-deomitir-apartes-de-la-jep-antes-de-enviarla-sancion-presidencial-articulo-838547

eltiempo.com (2019, junio 18). Referendo contra JEP no tiene apoyo del partido uribista. Recuperado de https:/ / www.eltiempo.com/politica/partidos-politicos/referendocontra-jep-uribe-lo-apoya-pero-su-partido-no-ha-decidido-377480

eltiempo.com. (2019, junio 17). ¿Qué busca Uribe hablando nuevamente del «estado de opinión»? Recuperado de 2019 de https://www.eltiempo.com/politica/gobierno/que-busca-uribe-hablando-nuevamente-del-estado-de-opinion-376786

eltiempo.com (2019, mayo 30). «Si las tuviera que volver a presentar (objeciones a JEP), lo haría». eltiempo.com. Política. Recuperado de https://www.eltiempo.com/ politica/gobierno/duque-jesus-santrich-es-un-mafioso-tras-orden-de-libertad369586

eltiempo.com. (2015, abril 6). Por «corromper congresistas», condenan a exministros de gobierno Uribe. Corte responsabilizó a Sabas Pretelt y Diego Palacio en «Yidispolítica». Les dictó 6 años y 8 meses. Recuperado de https:/ / www.eltiempo .com/archivo/documento/CMS-15575295

eltiempo.com. (2019, mayo 3). Futuro de las objeciones, pendiente de un acuerdo político. eltiempo.com y Política. Recuperado de https://www.eltiempo.com/politica/ congreso/en-vivo-senado-vota-hoy-las-objeciones-de-duque-a-la-jep-354956

eltiempo.com (2019, abril 9). Debate sigue en Senado: radicaron ponencia negativa sobre objeciones a la JEP. eltiempo.com. Redacción política. Recuperado de https:/ /www.msn.com/es-co/noticias/JEP/debate-sigue-en-senado-radican-ponencianegativa-sobre-objeciones-a-la-jep/ar-BBVLzm3?ocid=ob-fb-esco-1523414846014

eltiempo.com. (2019, febrero 19). La polémica petición del senador Álvaro Uribe sobre la JEP. eltiempo.com. recuperado de https:/ / www.eltiempo.com/ politica/ partidos-politicos/por-que-el-expresidente-uribe-pide-que-eliminen-la-jep-328592 
Ferrajoli, L. (2006). Garantismo. Una discusión sobre derecho y democracia. Madrid: Editorial Trotta, S. A.

Foster, J.B. (2019) Imperialismo tardío. Monthly review, 7,11. Nueva Gaceta. Recuperado de https://monthlyreview.org/2019/07/01/late-imperialism y http:/ / nuevagaceta.co/inicio/imperialismo-tardio

Gobierno Nacional y FARC-EP. (12 de noviembre de 2016). Acuerdo final para la terminación del conflicto y la construcción de una paz estable y duradera. Recuperado de https:// www.mesadeconversaciones.com.co/sites/default/files/121479102292.11-1479102292.2016nuevoacuerdofinal-1479102292.pdf

Hitler, A. (2017). Mi lucha. Bogotá: Negret Books.

Huntington, S. (I-II Trimestres, 1999). La superpotencia solitaria. Ciencia Política. 50, 924. Bogotá: Tierra Firme Editores S. A., Colombia.

Justicia Especial para la Paz-JEP. (2019, junio 7). Sistema Integral de Verdad, Justicia, Reparación y No Repetición??. Recuperado de https://www.jep.gov.co/Paginas/ JEP/Sistema-Integral-de-Verdad-Justicia-Reparacion-y-NoRepeticion.aspx

Justicia Especial para la Paz-JEP (2019, junio 6). Presidente Duque sanciona Ley Estatutaria de la JEP. Comunicado 084 de 2019. Recuperado de https:// www.jep.gov.co/Sala-de-Prensa/Paginas/Presidente-Duque-sanciona-la-LeyEstatutaria-de-la-JEP.aspx

Justicia Especial para la Paz-JEP. (2019, febrero 19). Ley Estatutaria de la JEP «La Corte Constitucional ya dio la última palabra». Recuperado de https:/ / www.jep.gov.co/ Sala-de-Prensa/Paginas/Ley-Estatutaria-de-la-JEP - \%E2\% 80\%9CLa-Corte-Constitucional-ya-dio-la-\%C3\%BAltima-palabra\%E2\%80\%9D. aspx

Justicia Especial para la Paz JEP (2019a, febrero 19). ONU urge sanción de Ley Estatutaria de la JEP para garantizar los derechos de las víctimas. Recuperado de https://www.jep.gov.co/Sala-de-Prensa/Paginas/ONU-URGE-SANCI\% C3\%93N-DE-LEY-ESTATUTARIA-DE-LA-JEP-PARA-GARANTIZAR-LOS-DERECHOS-DE-LAS-V\%C3\%8DCTIMAS.aspx

Justicia Especial para la Paz-JEP (2019b, febrero 19). Consejo de Seguridad de ONU pide pronta aprobación de la Ley Estatutaria para la JEP. Recuperado de https:// www.jep.gov.co/Sala-de-Prensa/Paginas/Consejo-de-Seguridad-de-ONU-pidepronta-aprobaci\%C3\%B3n-de-la-Ley-Estatutaria-para-la-JEP.aspx

Justicia Especial para la Paz-JEP (2019c, febrero 19). Michelle Bachelet, alta Comisionada de la ONU para los DD. HH. pide celeridad en discusión de objeciones a la 
Ley Estatutaria de la JEP. Recuperado de https:/ / www.jep.gov.co/Sala-de-Prensa/Paginas/Michelle-Bachelet-,-Alta-Comisionada-de-la-ONU-pide-celeridad-endiscusi\%C3\%B3n-de-objeciones-a-la-Ley-Estatutaria.aspx

Justicia Especial para la Paz-JEP. (2019d). CIDH preocupada porque la JEP no cuenta con una Ley Estatutaria. Recuperado de https:/ / www.jep.gov.co/Sala-de-Prensa/ Paginas/CIDH-preocupada-porque-la-JEP-no-cuenta-con-una-Ley-Estatutaria. aspx

Kelsen, H. (1934). Esencia y valor de la democracia. Barcelona y Buenos Aires: Labor.

Locke, J. (1981). Ensayo sobre el gobierno civil. Madrid: Aguilar.

Lander, E. (2012). El fin de la democracia liberal: La desigualdad en las sociedades capitalistas post- democráticas. Transnational Institute, Amsterdam, Holanda. Recuperado de http://www.tni.org/es/paper/el-fin-de-la-democracia-liberal

Matias Camargo, S. (enero-junio, 2019). La Justicia Especial para la Paz (JEP), sus avances y sus obstáculos. Diálogos de Saberes, 50, 21-31. Universidad Libre (Bogotá). DOI: https://doi.org/10.18041/0124-0021/dialogos.50.2019.5403

Matias Camargo, S. (enero-junio, 2018). La Reforma Rural Integral y su implementación. Diálogos de Saberes, 48, 25-45. En línea file:///C:/Users/win7/Downloads/ Dialnet-LaReformaRuralIntegralYSuImplementacion-6916582\%20(2).pdf

Matias Camargo, S. (enero-junio, 2017). La Reforma Rural Integral, la terminación del conflicto armado y el problema agrario en Colombia. Artículo científico de investigación. Diálogos de Saberes, 46,19-39. En línea file:/ / C:/Users/ win7/Downloads/ Dialnet-LaReformaRuralIntegralLaTerminacionDelConflictoArm-6259184\% 20(3).pdf

Matias Camargo, S. (julio- diciembre, 2013). Neoliberalismo, neoconstitucionalismo y democracia. Diálogos de Saberes, 39, 69-86. En línea https://dialnet.unirioja.es/ servlet $/$ revista?codigo $=7554$

Medina, S. (2019). Hoy se realizará audiencia pública en Senado, sobre objeciones a la JEP. Recuperado de http:/ / www.senado.gov.co/actualidad/item/28850-mananase-realizara-audiencia-publica-en-senado-sobre-objeciones-a-la-jep

Molano Jimeno, A. (elespectador.com, 2019, abril 6). ¿«Cerco» al Congreso por objeciones a la Estatutaria de la JEP? elespectador.com. Recuperado de https:// www.elespectador.com/noticias/politica/cerco-al-congreso-por-objeciones-laestatutaria-de-la-jep-articulo-849062

Montesquieu, C. L. (1993). El espíritu de las leyes. Barcelona: Altaya. 
Mussolini, B. (1935). El fascismo. Firenzi: Valechi Editori.

Noticias 1. (14 de mayo de 2019). La Corte Constitucional hace perentoria la exigencia al secretario general del Senado. Canal 1. Secretos CMI - Sistema Informativo del Canal 1. Recuperado de https:// canal1.com.co/noticias/uno-dos-tres/uno-la-corte-constitucional-hace-perentoria-la-exigencia-al-secretario-general-del-senado/

Oficina de Comunicaciones del ex presidente Álvaro Uribe (2019, junio 15). Carta dirigida a la Editora de la revista Semana. Recuperada de Semana.com de https:/ /www.semana.com/nacion/articulo/estado-de-opinion-20-la-apuesta-politicade-uribe/619808

Orozco Tascón, C. (El Espectador, 2019, junio 29). «Hay indicios de rebrote paramilitar»: Camilo González Posso. Recuperado de https:/ / www.elespectador.com/hay-indicios-de-rebrote-paramilitar-articulo-868465

Orozco Tascón, C. (elespectador.com, 2019, junio 1). «Se aclaran las competencias y funciones de la JEP»: Patricia Linares. Recuperado de https:/ / www.elespectador. com/se-aclaran-las-competencias-y-funciones-de-la-jep-articulo-863834

Payne, S.G. (1985). Falange. Historia del fascismo español. Madrid: Sarpe.

Pérez, D. (2019, junio 6). Uribe propone reemplazar a la JEP por sala especial en Corte Suprema. El ex mandatario presentaría el próximo semestre una reforma constitucional en ese sentido, con el respaldo de su bancada. Recuperado de https:/ / www.lafm.com.co/ politica/uribe-propone-reemplazar-la-jep-por-sala-especial-en-corte-suprema

Pinto, L. C. (2019). Presidencia de la República presenta al Congreso objeciones a Ley Estatutaria de la JEP. Recuperado de http://www.senado.gov.co/actualidad/ item/28744-presidencia-de-la-republica-presenta-al-congreso-objeciones-a-leyestatutaria-de-la-jep

Presidencia de la República de Colombia (2019, junio 6). Ley 1957 de 2019. Estatutaria de la Administración de Justicia en la Jurisdicción Especial para la Paz. Diario Oficial nro. 50.976). Recuperado de https://id.presidencia.gov.co/Documents/ JEP/Ley-1957-06-Junio-2019-JEP.pdf

Presidente de la República de Colombia. (2019). Iván Duque Márquez. Objeciones gubernamentales por inconveniencia. Recuperado de file:///C:/Users/win7/ Downloads/objeciones_2.pdf

Procuraduría General de la Nación. Boletín 148. (11 de marzo de 2019). La Constitución de Colombia se respeta: Procurador General. Recuperado de https:// 
www.procuraduria.gov.co/portal/-La_Constitucion_de_Colombia_se_respeta_ Procurador_General.news

Publimetro. (2019, junio 4.). Colombia, en números rojos por asesinatos de líderes sociales.

República de Colombia. (2019, junio 6). Ley 1957 de 2019. Estatutaria de la Administración de Justicia en la Jurisdicción Especial para la Paz. Diario Oficial nro. 50.976). Recuperado de http://svrpubindc.imprenta.gov.co/diario/index.xhtml; jsessionid=6d32beeebe522bc9f39ee3182033 https:/ / www.jep.gov.co/Sala-dePrensa/Paginas/Presidente-Duque-sanciona-la-Ley-Estatutaria-de-la-JEP.aspx

Rivera, G. (2019, mayo 1). «Las objeciones fueron rechazadas ayer»: Guillermo Rivera, exministro del Interior. elespectador.com. Redacción Política. Recuperado de https:/ / www.elespectador.com/noticias/politica/las-objeciones-fueron-rechazadasayer-guillermo-rivera-exministro-del-interior-articulo-853213

Romero, S. (The New York Times, 2008, October 29). Colombian Army is accused of killing poor civilians and labeling them insurgents. Recuperado de https:/ / www.nytimes. com/2008/10/29/world/americas/29iht-colombia.4.17352270.html?

Rousseau, J.J. (1985). El Contrato social. Barcelona: Ediciones Orbis, S. A.

Santos, B. (2009). La Sociología Jurídica Crítica. Para un nuevo sentido común en el derecho. ILSA, Bogotá, Colombia.

semana.com. (2019, junio 20). Corte Suprema estudia si revoca a la magistrada militar Cristina Lombana. Recuperado de de file:/ / /F:/Corte\%20Suprema\%20estudia \%20si \%20revoca \% 20a \% 20la\%20magistrada \%20militar \%20Cristina \% 20Lombana \%20-\%20ELESPECTADOR.COM.html

Semana. (2019, junio 2). Frase de la semana. 1935, 17.

Semana. (2019, junio 2). ¡Resurrección! El caso Santrich se convirtió en un fuerte pulso de poder entre las altas cortes y el Gobierno. ¿Qué hay detrás de esa pugna y qué impacto tiene para el país? 1935, 27.

Semana. (2019, mayo 19). Gobierno. La venta de ISA, en marcha. 1933, p. 64.

Semana.com. (2017, agosto 5). «Hacer trizas» el acuerdo con las FARC: ¿es posible? Recuperado de https:/ / www.semana.com/nacion/articulo/uribismo-hara-trizasacuerdo-acuerdo-con-farc-esta-blindado/524529

semana.com. (2009, junio 5). Uribe: «El Estado de Opinión es la fase superior del Estado de Derecho». Recuperado de https:/ / lasillavacia.com/historia/2296 
semana.com. (2007, octubre 17). El presidente Álvaro Uribe y su asesor José Obdulio Gaviria. Recuperado de https://www.semana.com/on-line/articulo/el-gobiernoescuda-inteligencia-superior-alvaro-uribe-para-haber-atacado-samuel-moreno/ 89199-3

Uprimny, R. (2019). Audiencia pública. Cámara de Representantes. Objeciones gubernamentales al Proyecto de Ley Estatutaria de Administración de la JEP. 1 de abril de 2019. Recuperado de https:/ / cdn.dejusticia.org/wp-content/uploads/2019/ 04/Audiencia-C\%C3\%A1mara-de-Representantes-Objeciones-JEP_RUY.pdf

Villar Borda, L. (2009). La teoría pluralista del Estado de Kelsen y la globalización. En: Ramírez Cleves, G. A. El derecho en el contexto de la globalización. Bogotá: Universidad Externado de Colombia, p. 135-157.

Yanes Guzmán, J. (1984). Particularidades del régimen fascista: ver libro "Chile recordando el futuro». Pensar lo pensado. Recuperado de https:/ / pensar-lopensado. com/ particularidades-del-regimen-fascista-ver-libro-chile-recordando-el-futuro/ 29.6.2019. 
